\title{
Perspektiven der antiinflammatorischen Pharmako- therapie der COPD: Neutrophile Granulozyten im Fokus
}

\author{
Novel Perspectives of COPD Pharmacotherapy: Focus on Neutrophils
}

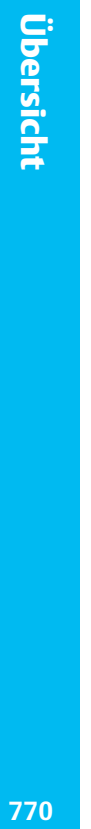

\section{Zusammenfassung}

Die bronchiale Entzündung der chronisch-obstruktiven Lungenerkrankung (COPD) ist durch eine Akkumulation neutrophiler Granulozyten in den Atemwegen betroffener Patienten gekennzeichnet. Gegenwärtig verfügbare Therapien haben jedoch einen allenfalls minimalen Einfluss auf neutrophile Entzündungsvorgänge. Daher werden große Anstrengungen unternommen, neue antiinflammatorische Therapieansätze der COPD zu entwickeln. Zahlreiche solcher Ansätze zielen auf die Reduktion von Neutrophilen in der Lunge bzw. Unterdrückung neutrophiler Effektorfunktionen. In der vorliegenden Übersicht werden aktuelle Forschungsergebnisse und daraus abgeleitete Therapiekonzepte zur inflammatorischen Pathogenese der COPD dargestellt. Insbesondere werden offene Fragen zum Entwurf adäquater klinischer Prüfungen, Möglichkeit und Grenzen geeigneter Zielparameter, sowie Aspekte zu Risiken und Verträglichkeit anti-neutrophiler Therapien kritisch beleuchtet.

\section{Abstract}

Inflammation in COPD is characterized by an increased presence and activation of airway neutrophils. However, since currently available treatment options have only limited effects on neutrophilic airway inflammation, great efforts are undertaken to develop novel therapies targeting the neutrophilic component of inflammation in COPD. The present review discusses the rationale for anti-neutrophilic treatment in COPD and provides a critical overview of recent developments in drug therapy. Moreover, open questions and limitations of clinical trials including choice of adequate outcome parameters for proof-of-concept studies with putative anti-neutrophilic drugs and potential safety issues are summarized.

\section{Hintergrund}

\section{Die Bedeutung neutrophiler Granulozyten bei COPD}

Die chronisch obstruktive Lungenerkrankung (COPD) ist durch eine Akkumulation inflammatorischer Zellen wie Neutrophile und Makrophagen in den Atemwegen betroffener Patienten charakterisiert [1 - 3]. Der Verlauf der Erkrankung ist in den meisten Fällen progressiv. Dieser Erkrankungsprogress, klinisch messbar als jährlicher Verlust an expiratorischer Ein-Sekundenkapazität
$\left(\mathrm{FEV}_{1}\right)$, wird auch durch die derzeitig verfügbaren Therapien nicht signifikant aufgehalten [4-7]. Bislang ist die Aufgabe des Rauchens die einzige Intervention, die diesen progredienten Verlust an Lungenfunktion bei COPD-Patienten aufhalten kann [8]. Allerdings besteht auch bei ehemaligen Rauchern die neutrophile Entzündung in den Atemwegen trotz Aufgabe des Rauchens zumindest partiell weiter, sobald die Erkrankung einmal manifestiert ist $[9,10]$. 
Das Ausmaß der neutrophilen Entzündung ist bei COPD positiv mit dem Schweregrad der Erkrankung [3], und zu einem gewissen Grad auch mit der Exazerbationshäufigkeit [11] korreliert. Insbesondere spielen eine Proteasen/Antiproteasen-Imbalance und oxidativer Stress eine dominante Rolle in der Pathogenese, Krankheitsprogression und irreversiblen Emphysementstehung bei COPD [12]. Neutrophile Granulozyten reagieren auf exogene und endogene Stimuli mit einer unmittelbaren Freisetzung von reaktiven Sauerstoffmetaboliten und elastolytischen Enzymen und sind somit eine der Hauptquellen von oxidativem Stress und proteolytischer Entzündungsmediatoren bei COPD. Neutrophile Granulozyten fördern in erster Linie durch Freisetzung der Neutrophilen-Elastase zudem die Mukusproduktion durch Becherzellen [13], und diese exzessive Mukusproduktion gilt als unabhängiger klinischer Prognosefaktor hinsichtlich der COPDMortalität [14]. Neutrophile sowohl des peripheren Blutes als auch der Lunge von COPD-Patienten weisen sowohl während stabiler Erkrankung als auch während einer Exazerbation einen erhöhten Aktivierungszustand auf [15-18] und die Aktivierung nimmt im Verlauf einer Exazerbation weiter zu [19,20]. Die Dominanz neutrophiler Granulozyten in den Atemwegen von COPD-Patienten ist mit einer Vermehrung proinflammatorischer Mediatoren wie Chemokinen [21 - 23], Elastase [24], Metalloproteasen [25-27], Zytokinen [28,29], nitrosativem [30-33] und oxidativem $[34,35]$ Stress assoziiert. Die Rekrutierung neutrophiler Granulozyten in das pulmonale Kompartiment wird über eine komplexe Abfolge von Signalprozessen reguliert. Nach einer initialen Anheftung („tethering“) Neutrophiler aus der Blutbahn erfolgt eine firme Adhäsion an Endothelzellen mit nachfolgender chemotaktischer Migration in Bronchialbaum, Atemwegslumina und Alveolarraum [36,37]. Insbesondere Interleukin (IL)-8, und Leukotrien $\mathrm{B}_{4}\left(\mathrm{LTB}_{4}\right)$ als potente Chemotaxine nehmen in der Initiierung und Aufrechterhaltung der Neutrophilenrekrutierung und -aktivierung eine Schlüsselrolle ein. Neben der vermehrten Rekrutierung aus dem Blut- und Marginalpool trägt zur Akkumulation neutrophiler Granulozyten bei COPD in den Atemwegen eine reduzierte Clearance von Neutrophilen bei [38]. Schließlich ist auch die Neutrophilen-Apoptose in den Atemwegen durch erhöhte lokale Konzentrationen von Survial-Faktoren wie Granulozyten-Makrophagen-Kolonie-stimulierenden Faktor bei COPD inhibiert [28].

Interessanterweise konnten einige [39], jedoch nicht alle [40] Autoren trotz einer massiven Vermehrung von Neutrophilen in BAL und induziertem Sputum keine erhöhte Neutrophilenanzahl in Biopsien peripherer Atemwege nachweisen. Jedoch haben neuere Arbeiten in glatter Bronchialmuskulatur von Rauchern mit COPD eine vermehrte Infiltration durch Neutrophile nachgewiesen. Dies wiederum könnte bedeuten, dass Neutrophile und ihre Mediatoren eine Schlüsselrolle in der Entstehung verdickter und vermehrt kontraktiler Bronchialmuskulatur bei COPD spielen könnten, da z.B. IL-8 aus Neutrophilen ein potentes Mitogen für glatte Muskeln darstellt [41]. Zusammenfassend unterstreichen diese Daten, dass nicht die reine Präsenz oder Vermehrung der Neutrophilen, sondern auch die exakte Lokalisation und Verteilung dieser Zellen in den betroffenen Atemwegen bei COPD von entscheidender Bedeutung ist. Dies wiederum beeinflusst sowohl die Auswahl therapeutischer Ansatzpunkte als auch insbesondere deren optimale Applikationsform (systemisch vs. inhalativ).
Angesichts der herausragenden Rolle neutrophiler Entzündungsvorgänge bei COPD ist die Reduktion der Neutrophilie seit längerem ein Ansatzpunkt kontrollierter klinischer Studien. Aufgrund positiver Erfahrungen in der Asthmatherapie lag es zunächst nahe, den Effekt inhalativer bzw. systemischer Kortikoide auf die Entzündung bei COPD zu evaluieren. Die Ergebnisse dieser Studien haben jedoch keinen konsistenten Wirksamkeitsnachweis erbringen können. Vielmehr zeigte sich, dass inhalative Steroide bei COPD im Hinblick auf die neutrophile Entzündung von eher untergeordneter Bedeutung sind. Bezüglich entzündlicher Surrogatmarker zeigten sowohl hochdosierte inhalative als auch orale Steroide keinen $[42,43]$ oder einen allenfalls geringen $[44,45]$ Therapieeffekt bei stabiler COPD. In Langzeit-Studien konnten hochdosierte inhalative Steroide zudem den progressiven Abfall der Lungenfunktion bei mittelschwerer bis schwerer COPD nicht aufhalten $[4,6,7]$. Jedoch konnte in bestimmten Patientengruppen durch die Einnahme inhalativer Steroide eine Reduktion der Exazerbationshäufigkeit und eine verlangsamte Verschlechterung des allgemeinen Gesundheitsstatus erreicht werden [4]. Erst kürzlich wurde die Hypothese aufgestellt, dass die bei COPD-Patienten beobachtete relative Steroid-Resistenz möglicherweise durch eine Inaktivierung von Histon-Deazetylase verursacht wird [46], was dazu führt, dass proinflammatorische Gene nicht abgeschaltet werden. Folgerichtig werden in den aktuellen Behandlungsleitlinien der COPD auch Bronchodilatatoren als Mittel der ersten Wahl empfohlen [47], während der Einsatz inhalativer Steroide nur bei Patienten mit mittelschwerer bis schwerer COPD und rezidivierenden Exazerbationen befürwortet wird. Angesichts dieser eher ernüchternden Daten ergibt sich daher ein dringender Bedarf an neuen, antientzündlichen Therapieoptionen für die COPD.

\section{Mögliche Angriffspunlkte anti-neutrophiler Therapien}

\section{Mechanismen neutrophiler Entzündung}

Bei der Rekrutierung neutrophiler Granulozyten in die Atemwege sind eine Reihe von Mechanismen involviert: Chemotaxine wie IL-8, LTB-4, Growth-related-oncogen (GRO)-alpha, transendotheliale Einwanderung von Neutrophilen über Selektinabhängige Anheftungsprozesse, sowie nachfolgende Adhäsion über $\beta$-Integrin-gesteuerte Mechanismen [36] wie z.B. die Bindung von CD11b/CD18 (Mac-1) an interzelluläres Adhäsionsmolekül (ICAM) -1 [37]. Am Ort der Entzündung werden Neutrophile durch vielzählige Stimuli aktiviert, was wiederum zu einer Freisetzung von proteolytischen Enzymen, Zytokinen und schließlich oxidativem Stress führt. Zusätzlich ist im entzündlich veränderten Gewebe die Clearance bzw. Apoptose von Neutrophilen durch Überlebensfaktoren wie GM-CSF verzögert [48].

\section{Chemotaxis}

\section{IL-8-Antagonisten}

IL-8 aus der Gruppe der CXC-Chemokine, ist ein sehr potentes Neutrophilenchemotaxin [37,49]. Es besteht eine konsistente Korrelation zwischen IL-8-Konzentrationen und neutrophiler Entzündung. So ist sowohl eine Neutrophilie im Sputum, als auch in der BAL und in Biopsien direkt positiv mit IL-8-Konzentrationen desselben Mediums korreliert. Dabei nimmt man an, dass bronchiale Epithelzellen und Makrophagen die Hauptquelle von IL-8 in den Atemwegen darstellen. Die Freisetzung von IL-8 
wird über verschiedene Wege vermittelt [50]. Bei COPD ist die Konzentration von IL-8 in den Atemwegen stark erhöht [21], steigt während Exazerbationen weiter an [11] und trägt wesentlich zur chemotaktischen Gesamtaktivität von Atemwegssekreten gegenüber Neutrophilen bei [51]. In der BAL zeigen erhöhte IL-8-Spiegel eine vermehrte Anfälligkeit von Rauchern für die Entstehung eines Lungenemphysems an [52]. Erhöhte IL-8-Konzentrationen in Verbindung mit Atemwegsneutrophilie finden sich auch bei Asthma bronchiale [53,54], zystischer Fibrose [55], idiopathischer Lungenfibrose [56] und obliterativer Bronchiolitis nach Lungentransplantation [57]. IL-8 stellt darüber hinaus einen wichtigen Entzündungsmediator bei rheumatoider Arthritis dar [58] und fördert die Tumormetastasierung, insbesondere beim malignen Melanom [59,60]. Daher wird die Antagonisierung von IL-8 als attraktiver therapeutischer Ansatzpunkt seit einigen Jahren verfolgt [61], in erster Linie durch monoklonale anti-IL-8-Antikörper [61]. Präklinische Daten bei Primaten deuteten eine gute Verträglichkeit von anti-IL-8 an [62]. Bislang wurde kürzlich eine klinische Studie zur Wirksamkeit eines monoklonalen anti-IL-8-Antikörpers bei COPD publiziert. In dieser dreimonatigen, randomisierten Studie reduzierte anti-IL-8 gegenüber Plazebo die Dyspnoesymptomatik, ohne jedoch Lungenfunktion oder Belastungskapazität zu verbessern. Darüber hinaus wurden in dieser Studie keine Entzündungsmarker untersucht [63]. In Anbetracht der Schlüsselrolle, die IL-8 bei der Infektabwehr spielt, stellt die systemische und eventuell auch dauerhafte Blockade von IL-8 in jedem Falle ein potenzielles Risiko für COPD-Patienten dar.

Einen alternativen Ansatzpunkt zur Inhibition der biologischen Effekte chemotaktischer Mediatoren wie IL-8 stellt die Antagonisierung des komplementären Rezeptors auf der Zelloberfläche dar. Zur Realisierung dieses Ansatzpunktes sind mehrere CXCChemokin-Rezeptor-Antagonisten entwickelt worden. In Tiermodellen sind diese Substanzen in der Lage, Neutrophileneinstrom und -chemotaxis wirksam zu unterbinden [64]. Klinische Daten beim Menschen liegen bislang jedoch nicht vor [65].

\section{Leukotrien (LT)-B B $_{4}$-Antagonisten}

$\mathrm{LTB}_{4}$ gehört neben IL-8 zu den potentesten Neutrophilenchemotaxinen und -aktivatoren. Nach spezifischer (BLT)-Rezeptorbindung vermittelt $\mathrm{LTB}_{4}$ über intrazellulären $\mathrm{Ca}^{++}$-Einstrom transmembranöse Potenzialschwankungen, Exozytose und Degranulation, vermehrte Expression von $\beta$-Integrinen auf Zellmembranen (CD11b/18) und letztlich gesteigerte Chemotaxis [66]. Dementsprechend sind CD11b/CD18 auch auf Neutrophilen von Rauchern hochreguliert, und diese vermehrte Expression von Adhäsionsmolekülen ist klinisch mit der Atemwegsobstruktion korreliert [15]. Die intratracheale Applikation von $\mathrm{LTB}_{4}$ hat einen massiven Einstrom von Neutrophilen in den bronchoalveolären Raum beim Menschen zur Folge [67]. Bei COPD-Patienten lassen sich erhöhte $\mathrm{LTB}_{4}$-Spiegel im Serum und in der BAL nachweisen $[68,69]$. LTB 4 bewirkt neben IL-8 den Großteil der neutrophilen chemotaktischen Aktivität von Atemwegssekreten von COPD-Patienten $[51,70]$. Im Atemkondensat steigt die $\mathrm{LTB}_{4}$ Konzentration während einer COPD-Exazerbationen an und fällt unter Therapie wieder ab [71]. Schließlich wird auch die Apoptose von Neutrophilen durch $\mathrm{LTB}_{4}$ inhibiert [72].
Eine Aufhebung der biologische Effekte von $\mathrm{LTB}_{4}$ kann prinzipiell durch zwei verschiedene Mechanismen erreicht werden. Zum einen kann die $\mathrm{LTB}_{4}$-Synthese blockiert werden, z. B. über eine Blockade des Schrittmacherenzyms der $\mathrm{LTB}_{4}$-Synthese, der 5-Lipoxygenase. Alternativ können auch $\mathrm{LTB}_{4}$-Rezeptorantagonisten über eine Blockade von $\mathrm{LTB}_{4}$-Rezeptoren an der Zelloberfläche die Wirkung von $\mathrm{LTB}_{4}$ inhibieren. Zileuton ist ein Inhibitor des 5-Lipoxygenase-Aktivator-Proteins (FLAP), der für die Behandlung von Asthma bronchiale zugelassen ist. Bei Asthmatikern wirkt dieses Medikament in erster Linie auf die eosinophile Entzündung über eine Reduktion der Cysteinyl-Leukotriensynthese. Aufgrund des gemeinsamen Schrittmacherenzyms der Cys-Leukotrien- und $\mathrm{LTB}_{4}$-Synthese liegt bei COPD das Augenmerk allerdings auf einer potenziellen Beeinflussung der neutrophilen Entzündung durch 5-Lipoxygenase-Hemmer oder FLAP-Inhibitoren. Bislang sind erst wenige klinische Daten hierzu veröffentlicht. In einer kontrollierten Studie führte eine zweiwöchige Behandlung mit dem Leukotrien-Synthese-Inhibitor BAYx1005 zu einer geringen Reduktion der LTBC-Konzentration in den Atemwegen, ohne jedoch klinische Effekte hervorzubringen [73].

Darüber hinaus sind mindestens drei $\mathrm{LTB}_{4}$-Rezeptorantagonisten in „proof-of-concept“-Studien beim Menschen eingesetzt worden: LTB019A (Novartis), LY293111 (Lilly) und BI-56042 (Boehringer, rheumatoide Arthritis). LY293111 konnte beim Meerschweinchen den Neutrophileneinstrom gemessen in der BAL nach Allergenprovokation unterdrücken [74]. In einer weiteren Studie mit leichten Asthmatikern wurde zwar die Atemwegsneutrophilie nach Allergenprovokation unterdrückt, allerdings ohne messbaren klinischen Effekt auf die Atemwegsobstruktion im Rahmen der allergischen Spätreaktion [75]. Erste Daten aus Studien bei COPD sind bislang enttäuschend, da weder ein positiver Effekt auf Neutrophilenzahl (z.B. Sputum) noch auf Surrogatmarker der neutrophilen Entzündung gezeigt werden konnte [76]. Daher muss die Realisierbarkeit dieses therapeutischen Ansatzes kritisch hinterfragt werden.

\section{Zellmigration Selektinantagonisten}

Die Entzündungskaskade bei COPD und Asthma folgt einer regulierten Abfolge von Signalen und interzellulärer Kommunikation, die letztlich eine Akkumulation von inflammatorischen Zellen im bronchialen Gewebe bewirkt. Eines der frühen Ereignisse im Ablauf der Zellrekrutierung aus dem Blutpool stellt das Anheften von Blutleukozyten an vaskulären Endothelien im Kapillarbett der Lunge dar. Die initiale Anheftung wird in erster Linie durch Selektine aus der Gruppe der Zelladhäsionsmoleküle vermittelt. Zu den Selektinen gehören P-, L-, and E-Selektin. Deren Liganden wie CD34, P-Selektin-Glykoprotein-Ligand (PSGL) und Sialyl Lewis $\mathrm{X}$, sind bei chronisch-entzündlichen Atemwegserkrankungen vermehrt nachweisbar [77], während z.B. die Expression von L-Selektin auf zirkulierenden Leukozyten während einer Asthmaexazerbation reduziert sein kann [78]. Während die Rolle der Selektine bei Asthma u.a. durch Tiermodelle allergischer Entzündung relativ gut charakterisiert ist, ist die Bedeutung der Selektine für die Pathogenese der COPD weitaus weniger erforscht [79]. In verschiedenen Tiermodellen konnte eine Selektin-vermittelte Rekrutierung von Neutrophilen in akut entzündliches Gewebe nachgewiesen werden [80]. Darüber hinaus konnte mittels spezifischer Selektin-Antagonisten und Selektin- 
„knock-out“-Mäusen klar gezeigt werden, dass Selektine eine zentrale Bedeutung in der Vermittlung entzündlicher Zellinfiltration sowohl bei akuten als auch chronischen Krankheitsprozessen haben [81-83].

Bislang wurde ein synthetischer Selektin-Antagonist, TBC 1269 (Texas Biotechnologies) in ersten klinischen Studien bei Patienten mit Asthma bronchiale und Psoriasis eingesetzt. TBC1269 (Bimosiamose = 1,6-Bis [3-(3-carboxymethylphenyl)4-(2- $\alpha$-D-mannopyrano-syloxy)-phenyl] hexane) ist ein synthetischer Pan-Selektin-Antagonist, der gegen alle drei bislang identifizierten Selektine gerichtet ist [84]. In vitro blockiert TBC1269 die transendotheliale Migration verschiedene Leukozyten-Subklassen, mit einer deutlich erhöhten Präferenz für Neutrophile [85]. Im allergischen Schafmodell konnten durch die inhalative Verabreichung von TBC1269 allergeninduzierte Atemwegsobstruktion und neutrophile Entzündung unterbunden werden [80]. Im Rahmen einer klinischen Studie wurde Asthmatikern vor der Durchführung einer Allergenprovokation eine intravenöse Einzeldosis TBC1269 verabreicht; die intravenöse Gabe inhibierte in geringem Maße die allergeninduzierte Sputumeosinophilie gegenüber Plazebo, war jedoch ohne Effekt auf die asthmatische Spätreaktion [86]. Im Gegensatz dazu konnte in einer randomisierten, Plazebo-kontrollierten Phase-II-Studie bei leichten Asthmatikern eine Inhibition der allergischen Spätreaktion um fast 50\% gegenüber Plazebo durch wiederholte Inhalation von $70 \mathrm{mg}$ TBC1269 erreicht werden [87]. In Übereinstimmung mit tierexperimentellen Daten bestätigte diese Studie bei Asthmatikern die Überlegenheit der inhalativen gegenüber der systemischen Applikation von TBC1269. Ursache hierfür ist möglicherweise die Bedeutung von Selektinen bei der Freisetzung proinflammatorischer Mediatoren und der Signaltransduktion von Entzündungsprozessen [88-90]. Im o.g. Schafmodell bewirkte die Behandlung mit TBC1269 u.a. eine deutliche Reduktion der Konzentration von Mastzell-Mediatoren wie Histamin und Kallikrein in der BAL. Die inhalative Darreichungsform bietet im Hinblick auf potenzielle Nebenwirkungen zweifellos Vorteile gegenüber einer systemischen Applikation bei Atemwegserkrankungen.

\section{Neutrophilenaktivierung und Mediatorfreisetzung Adenosin-A2a-Rezeptoragonisten}

Eine Stimulation von Nukleotidrezeptoren wie dem AdenosinA2a-Rezeptor auf Neutrophilen inhibiert eine Vielzahl proinflammatorischer Effektormechanismen wie die Freisetzung von Sauerstoffradikalen, Elastase, Myeloperoxidase und die verstärkte Adhärenz Neutrophiler an Gefäßendothelien im Rahmen von Entzündungsvorgängen [91]. Daher eröffnen A2a-Rezeptoragonisten einen möglichen Therapieansatz bei COPD, Asthma bronchiale oder allergischer Rhinitis. Zwei Vertreter dieser Substanzklasse (CGS21680, Novartis und GW328267, GlaxoSmithKline) wurden bislang im Tierversuch bzw. ersten klinischen Studien geprüft. In sensibilisierten Ratten konnte durch CGS21680 die Entzündungsreaktion nach Allergenprovokation unterdrückt werden [92]. Erste Erfahrungen mit GW328267 in einer Allergenprovokations-Studie bei leichten Asthmatikern waren allerdings enttäuschend [93]. Daten zum Einsatz bei COPD liegen nicht vor. Es bleibt daher offen, ob sich aus diesem Ansatz eine effektive Therapie für COPD und Asthma entwickeln kann.

\section{Elastase- und Metalloproteinase-Inhibitoren}

Neutrophile Granula enthalten verschiedene Proteasen, die unter physiologischen Umständen z.B. während einer antimikrobiellen Abwehrreaktion freigesetzt werden. Eine dieser Proteasen ist die Neutrophilen-Elastase, die insbesondere bei der Pathogenese des Lungenemphysems eine Schlüsselrolle spielt. Bei Patienten mit stabiler COPD finden sich konsistent erhöhte Konzentrationen von Elastase, und diese erhöhten Elastase-Spiegel werden nicht von einem gleichsinnigen, regulatorischem Anstieg endogener Antiproteasen begleitet [94,95]. Dieses Phänomen tritt während einer Exazerbation in noch stärkerem Maße auf. Insbesondere das Ausmaß einer unzureichenden Neutralisation von neutrophiler Elastase durch endogene Inhibitoren (in erster Linie alpha-1-Antitrypsin) korreliert mit der Schwere der neutrophilen Entzündung und dem emphysematösem Lungenumbau $[96,97]$. Im Tierversuch (Ratte und Meerschweinchen) führt die intratracheale Applikation von Elastase zu einer hochgradigen Entzündung der Atemwege mit emphysematöser Zerstörung der Alveolararchitektur [98]. Im Gegensatz dazu sind sog. Elastase-,,Knock-out“-Mäuse trotz kontinuierlicher, experimenteller Exposition gegenüber Zigarettenrauch gegen eine Emphysementstehung resistent [99].

Neben der etablierten Substitutionstherapie mit alpha-1-Antitrypsin bei homozygotem, hereditären Mangelemphysem zur Wiederherstellung einer Proteasen/Antiproteasen-Balance sind in den vergangenen Jahren zahlreiche spezifische Elastase-Inhibitoren für die Therapie von COPD, zystischer Fibrose und akutem Lungenversagen entwickelt worden [100]. Allerdings wiesen die meisten synthetisch hergestellten Elastase-Inhibitoren bislang entweder inakzeptable Nebenwirkungen auf oder waren wirkungslos [101]. In Zukunft könnte die inhalative Substitutionstherapie mit rekombinantem alpha-1-Antitrypsin auch bei COPD-Patienten ohne hereditären alpha-1-Antitrypsinmangel eine potenzielle Alternative darstellen [102].

Neben der Neutrophilen-Elastase sind die Matrixmetalloproteasen (MMPs) essentiell für die Homöostase extrazellulärer Matrix unter physiologischen und pathologischen Bedingungen [103]. Die Hauptquelle endobronchialer MMPs stellen Entzündungszellen in den Atemwegen dar, insbesondere neutrophile Granulozyten [104]. Von allen bisher bekannten MMPs wurde die Rolle der MMP-9 bei entzündlichen Atemwegserkrankung am intensivsten untersucht [105]. Neben seiner Bedeutung bei der Tumorinvasion und -metastasierung vermittelt MMP-9 z.B. bei chronischem Asthma Atemwegs-Remodelling und subepitheliale Fibrose $[106,107]$. Zudem findet man erhöhte Sputumkonzentrationen von MMP-9 nach spezifischer Allergenprovokation [108] oder während Asthma-Exazerbationen [109]. Bei Rauchern und COPD-Patienten konnte ebenfalls eine vermehrte MMP-9-Sekretion aus Alveolarmakrophagen nachgewiesen werden. Im Sputum-Überstand von Patienten mit COPD oder chronischer Atemwegsobstruktion im Rahmen einer obliterativen Bronchiolitis nach Lungentransplantation konnten ebenfalls erhöhte MMP-9-Konzentration gemessen werden $[26,110]$. Expression und Aktivierung von MMP-9 werden über verschiedene proinflammatorische Zytokine wie z.B. TNF-alpha, reguliert [111 - 113]. Einen physiologischen Antagonisten der MMPs stellen die so genannten "Tissue-inhibitors of Metalloproteases“ (TIMP) dar. Ein Ungleichgewicht zwischen MMP-9 und dem en- 
dogenen Inhibitor TIMP-1 konnte sowohl im Serum [114] als auch im induzierten Sputum [109] von Asthmatikern nachgewiesen werden. Dabei war das Ausmaß des Ungleichgewichtes, gemessen als äquimolare Ratio MMP-9: TIMP-1 mit klinischen Parametern und der Lungenfunktion korreliert.

Angesichts der Bedeutung der MMPs für die Tumorprogression sind zur Prävention von Metastasen maligner Tumoren unlängst selektive MMP-Inhibitoren entwickelt worden, von denen sich Marimastat in fortgeschrittenen Phasen klinischer Studien befindet. Allerdings sind die Daten zur Wirkung von Marimastat in onkologischen Studien bislang umstritten [115], Ergebnisse zu Effekten bei nicht-malignen, chronisch entzündlichen Erkrankungen liegen aktuell nicht vor.

\section{TNF-alpha-Blocker}

Zur therapeutischen Blockade des proinflammatorischen Zytokins TNF-alpha sind bislang sowohl humanisierte monoklonale Antikörper gegen TNF als auch gegen lösliche TNF-Rezeptoren entwickelt worden. Diese Medikamente sind entweder für die Behandlung der schweren rheumatischen Arthritis, der ankylosierenden Spondylitis, Morbus Crohn oder der psoriasiformen Arthritis zugelassen [116]. TNF spielt in der inflammatorischen Pathogenese neben Asthma bronchiale, allergischer Rhinitis, idiopathischer Lungenfibrose oder obliterativer Bronchiolitis auch bei COPD eine wichtige Rolle. Bei COPD-Patienten fördern erhöhte TNF-Konzentrationen u.a. durch Aktivierung von MMP-9 irreversibles Remodelling und Emphysementstehung [25]. TNF-alpha ist bereits in der BAL von Rauchern gegenüber Nichtrauchern erhöht [117]. Zigarettenrauch selber verstärkt die TNF-alpha-Freisetzung aus Alveolarmakrophagen von COPD-Patienten [118]. Zumindest in der taiwanesischen Bevölkerung lässt sich zudem ein genetischer Zusammenhang zwischen einem TNF-alpha-Polymorphismus mit erhöhten TNF-Spiegeln und dem Auftreten einer COPD untermauern [119]. Schließlich scheinen erhöhte TNF-Spiegel auch für eine Reihe der systemischen Effekte der COPD (wie z.B. das wasting) verantwortlich zu sein und mit einer schlechteren Prognose einherzugehen [120]. Auch bei schwerem Asthma lassen sich erhöhte TNF-Konzentrationen z. B. im induzierten Sputum nachweisen [54]. Daher stellt die TNF-Blockade prinzipiell auch bei COPD und schwerem Asthma einen potenziellen therapeutischen Ansatz dar.

Dennoch kann allein aufgrund erhöhter TNF-alpha-Spiegel bei einigen der o.g. genannten Atemwegserkrankungen nicht notwendig auf eine kausale Rolle von TNF bei der Krankheitsentstehung oder -progression geschlossen werden. Auch haben vermehrte Berichte über schwere Infektionen oder Lymphom-Entstehung unter Therapie mit TNF-Blockern neue Fragen über die langfristige Sicherheit dieses Ansatzes aufgeworfen [121,122]. Gerade bei COPD-Patienten, bei denen häufig eine bakterielle Besiedlung oder sogar aktive Infektion der Atemwege vorliegt, muss man den möglichen Vorteil einer TNF-Blockade gegenüber den damit verbundenen Risiken genau abwägen. Zudem ist die Rolle von TNF bei aktuellen Indikationen für TNF-Blocker wie rheumatoider Arthritis besser etabliert als bei der COPD, und man verfügt anders als bei COPD über verlässliche, auch kurzfristig klinisch erfassbare Erfolgsparameter wie Schmerzen und Gelenkschwellung. Angesichts dessen kamen auch die negativen Ergebnisse der ersten Pilotstudie bei COPD nicht überraschend
[123]. Schlussendlich müssen natürlich auch die hohen Kosten einer solchen Therapie in Betracht gezogen werden.

Einen alternativen Ansatzpunkt stellen TNF-alpha konvertierendes Enzym (TACE)-Inhibitoren bzw. duale TACE- und MMP-Inhibitoren dar, die sich derzeit in Entwicklung befinden [124]. Klinische Daten liegen allerdings bislang nicht vor.

\section{Phosphodiesterase-(PDE)-IV-Inhibitoren}

In vergangenen Jahren wurden zahlreiche Inhibitoren der Phosphodiesterase (PDE) IV zur Behandlung von Asthma und COPD entwickelt $[125,126]$. Im Gegensatz zu Theophyllin, einem nichtselektiven PDE-Inhibitor, sollen diese neuen Substanzen durch selektive PDE-IV-Hemmung den Vorteil einer verbesserten bronchodilatatorischen Potenz und einer verstärkten anti-entzündlichen Wirksamkeit bieten, da PDE IV hauptsächlich in pulmonalen Entzündungszellen gefunden wird und neben anderen Effektorfunktionen auch die Freisetzung radikaler Sauerstoffverbindungen sowie Eosinophilen- und Neutrophilenchemotaxis vermittelt [127-129]. PDE-IV-Hemmer reduzieren proinflammatorische Effekte von Neutrophilen und Makrophagen von COPD-Patienten ex vivo [130]. Zusätzlich reduzieren sie die LPSstimulierte Freisetzung von TNF-alpha aus Blutzellen ex vivo [131]. Ähnlich wie in der Klasse der Neutrophilen-Elastase-Inhibitoren existieren zahlreiche Moleküle mit PDE-IV-hemmenden Eigenschaften. Allerdings wurde auch hier die klinische Entwicklung vieler Substanzen aufgrund ungünstiger Nebenwirkungen oder mangelnder klinischer Effektivität kompliziert (z.B. CDP-840, Merck/CellTech, D-4418, Schering-Plough, ausführliche Übersicht bei Souness u. Mitarb. [132]). Zur Zeit befinden sich Cilomilast (GlaxoSmithKline) und Roflumilast (Altana Pharma) in fortgeschrittenen Phasen klinischer Erprobung. Sowohl Cilomilast als auch Roflumilast erwiesen sich in klinischen Studien bei allergischer Rhinitis [133], Asthma bronchiale oder mittelschwerer bis schwerer COPD [131] als wirksam [134,135]. Trotz dieser initial optimistisch stimmenden Resultate ist bislang nicht klar, ob die klinischen Effekte bei obstruktiven Atemwegserkrankungen eher durch die bronchodilatatorischen oder antientzündlichen Eigenschaften dieser Substanzen vermittelt werden [136]. In einer an COPD-Patienten durchgeführten Biopsie-Studie führte Cilomilast zu einer moderaten Reduktion gewebeständiger neutrophiler Granulozyten und CD8(+)-Lymphozyten [137]. Dennoch ist die klinische Relevanz dieser Effekte noch unklar und es bleibt Aufgabe prospektiver klinischer Studien, die mittelund langfristige antiinflammatorische Wirksamkeit dieser Substanzen bei COPD zu beurteilen. Die amerikanische Zulassungsbehörde (US Food and Drud Administration, FDA) hat im Jahr 2003 eine Zulassung von Cilomilast als Dauertherapie der COPD aufgrund unzureichender klinischer Wirkung und weiterhin offener Sicherheitsaspekte, in erster Linie gastrointestinale Blutungen bzw. ischämische Kolitis abgelehnt (http://www.fda.gov/ ohrms/dockets/ac/03/briefing/3976b1.htm). Durch diese Entscheidung ist die Diskussion um das therapeutische Potenzial der PDE-IV-Inhibitoren erneut angeheizt worden. Da auch bei neueren oral verabreichten Substanzen z.B. gastrointestinale Nebenwirkungen ein relevantes klinisches Problem darstellen, könnte eine inhalative Applikationsform eine wünschenswerte Alternative darstellen. AWD 12-281, ein inhalativer PDE-IV-Inhibitor, befindet sich momentan in der klinischen Erprobung [138]. Falls sich erweisen sollte, dass die inhalative Darreichungs- 
form vergleichbare Wirksamkeit wie orale Präparate bei besserer Verträglichkeit zeigt, ist die inhalative Applikation möglicherweise der zukünftige Therapieansatz der ersten Wahl.

\section{Makrolide}

Makrolidantibiotika werden üblicherweise als Breitbandtherapeutika für eine Vielzahl von bakteriellen Infektionen eingesetzt. Neben antibiotischen Eigenschaften weisen Makrolide jedoch eine Reihe zusätzlicher antiinflammatorischer Effekte auf, die nicht an die Eradikation von Mikroorganismen gekoppelt sind. Dies wurde bislang am deutlichsten in der Behandlung der diffusen Panbronchiolitis demonstriert [139]. In vitro inhibieren Makrolide die Neutrophilenrekrutierung über eine Reduktion der Expression von Adhäsionsmolekülen, die Produktion reaktiver Sauerstoffmetaboliten und Freisetzung proinflammatorischer Zytokine wie TNF-alpha [140]. Daher gelten Makrolide als potenzielle neue antiinflammatorische Therapieoption bei COPD und schwerem Asthma. Bei Asthmatikern liegen Ergebnisse aus zahlreichen klinischen Studien mit Troleandomycin, Roxithromycin oder Clarithromycin vor, die geringe positive Effekte auf Symptomatik und Entzündungsmarker zeigen [141,142], jedoch ohne konsistenten Effekt auf die Lungenfunktion [141-143]. Allerdings wurden die meisten dieser Studien an Asthmatikern mit Zeichen einer Chlamydien- oder Mykoplasmeninfektion durchgeführt, daher muss bezweifelt werden, ob die beobachteten Effekte auf die antiinflammatorischen Eigenschaften der Makrolide zurückzuführen sind [144].

Bei japanischen COPD-Patienten reduzierte eine niedrigdosierte Dauertherapie mit Erythromycin die Exazerbationshäufigkeit und das Auftreten respiratorischer Infekte [145]. Im Hinblick auf Entzündungsmarker bei COPD sind die Resultate jedoch uneinheitlich. In zwei kleineren Studien mit Clarithromycin konnte in der einen eine signifikante Reduktion der Sputumzellzahl, Sputum-IL-8 und -TNF-alpha nachgewiesen werden [146], während in der zweiten Studie kein Effekt auf inflammatorische Parameter und Sputumneutrophilie zu verzeichnen war [147]. In jedem Fall rechtfertigen die bisherigen Ergebnisse die Durchführung größer angelegter Studien bei COPD-Patienten, dies insbesondere angesichts der guten Verträglichkeit von Makroliden und der relativ niedrigen Behandlungskosten von Substanzen wie Roxithromycin.

\section{Antioxidanzien}

Oxidativer Stress entsteht in den Atemwegen u. a. durch Vermehrung und Aktivierung neutrophiler Granulozyten, die Sauerstoffradikale als Teil der „innate“-Immunabwehr bilden. Zum Schutz vor diesen Radikalen existieren verschiedene sowohl zelluläre als auch nicht-zelluläre endogene Antioxidanzien. Bei vielen chronisch-entzündlichen Erkrankungen scheinen jedoch die endogenen Schutzmechanismen nicht auszureichen, um eine vermehrte Belastung mit reaktiven Sauerstoffspezies zu neutralisieren. Bei der idiopathischen Lungenfibrose z.B. spielt die Depletion des physiologischen pulmonalen Antioxidanz Glutathion $[148,149]$ eine zentrale Rolle in der Pathogenese. Seit langem werden daher Versuche unternommen, das Ungleichgewicht zwischen Antioxidanzien und Oxidanzien wieder herzustellen, beispielsweise durch die inhalative oder systemische Zufuhr von Glutathion-Präkursoren wie N-Acetylcystein (NAC) $[150,151]$. Auch bei allergischer Rhinitis, Asthma bronchiale
[152], obliterativer Bronchiolitis [153,154] und im besonderen Maße auch COPD [155] wurde vermehrter oxidativer Stress gezeigt. Dabei scheint oxidativer Stress bei COPD von besonderer Bedeutung zu sein, da Zigarettenrauch selbst große Mengen an Oxidanzien enthält, die in der Lage sind, direkt akute und chronisch-persistierende Entzündungsprozesse zu initiieren bzw. unterhalten. Während Exazerbationen der COPD steigt die oxidative Belastung sogar noch weiter an [34,71]. Infolgedessen gelten Antioxidanzien als potenzieller anti-entzündlicher Therapieansatz bei COPD. Bereits in der Vergangenheit konnte gezeigt werden, dass durch orales NAC, einem preiswerten und i.d.R. frei verkäuflichen Medikament mit guter Verträglichkeit, die Exazerbationshäufigkeit bei Patienten mit chronischer Bronchitis reduziert wird [156-158]. Darüber hinaus bewirkte NAC eine Reduktion von Wasserstoffperoxid $\left(\mathrm{H}_{2} \mathrm{O}_{2}\right)$ im Atemkondensat von COPD-Patienten $[159,160]$. Allerdings blieben in einer randomisierten, kontrollierten klinischen Studie für die Langzeitbehandlung mit NAC bei milder-mittelschwerer COPD (BRONCUS-Studie) die primären Zielparameter wie jährlicher Abfall der Lungenfunktion und Exazerbationshäufigkeit von der Behandlung unbeeinflusst [161]. Darüber hinaus gab es in der Behandlungsgruppe Hinweise auf eine Abnahme der Überblähung im Gesamtkollektiv und auf eine Reduktion der Exazerbationsrate in einer Subgruppe von Patienten, die keine inhalativen Steroide erhielten. Ergänzend wurden zudem auch erste Langzeitergebnisse zur NAC-Behandlung von Patienten mit idiopathischer Lungenfibrose auf dem Kongress der European Respiratory Society 2004 präsentiert (IFIGENIA-Studie), die einen klaren Vorteil der zusätzlichen Behandlung mit NAC zur Standardtherapie belegen.

Die klinische Wirkung von NAC bei COPD scheint nicht auf mukolytischen Effekten zu beruhen, da andere Mukolytika wie beispielsweise Ambroxol keinen Effekt auf die COPD-Exazerbationsrate haben [162]. Zukünftige Behandlungsstrategien zur Wiederherstellung der pulmonalen Redox-Balance beinhalten in erster Linie stabile thiolhaltige Mukolytika wie Nacystelyn, das sowohl in vitro und in vivo $[163,164]$ antioxidative Eigenschaften aufweist. Nacystelyn wurde bislang in klinischen Studien mit Patienten, die an zystischer Fibrose litten, eingesetzt und konnte dort zumindest die Viskosität der Bronchialsekrete reduzieren [165]. Der Nachweis klinischer Effekte aufgrund antioxidativer Eigenschaften steht jedoch noch aus.

\section{Bedeutung fürr klinische Studien}

Ein bislang nicht zufriedenstellend gelöstes Problem stellt die Erfassung klinischer Effekte anti-neutrophiler Therapien bei entzündlichen Atemwegserkrankungen wie COPD im Rahmen von Studien dar. Da selbst eine signifikante Reduktion der Atemwegsneutrophilie nicht unmittelbar in einer einfach messbaren physiologischen Veränderung (z.B. Lungenfunktion) resultieren dürfte, stellt die Auswahl von primären Zielparametern in klinischen Studien zum Wirksamkeitsnachweis solcher Therapien eine echte Herausforderung dar. Beim allergischen Asthma bronchiale bietet das Allergenprovokationsmodell zumindest prinzipiell die Möglichkeit, dynamische Veränderung von Zellpopulationen der Atemwege zu untersuchen. Allerdings ist auch in diesem Modell der Zusammenhang zwischen allergeninduzierter 
Neutrophilie (genauso wie für die Eosinophilie [166]) und funktionellen Parametern der Obstruktion wie $\mathrm{FEV}_{1}$ letztlich nicht voll etabliert. Dies umso mehr, als gezeigt werden konnte, dass eine wirksame Inhibition der allergeninduzierten Neutrophilie ohne Effekt auf die asthmatische Spätreaktion war [75]. Alternativ stellen durch LPS, Platelet activating factor (PAF) [167] oder Endotoxin ausgelöste Atemwegsneutrophilien relativ etablierte Modelle - zumindest bei Gesunden und leichten Asthmatikern - dar [168]. Dennoch ist zweifelhaft, ob solche Modelle auch bei Patienten mit schwerem Asthma oder COPD Anwendung finden können. Erschwerend kommt für derartige dynamische Modelle hinzu, dass sie die „natürliche“ Erkrankung nur sehr eingeschränkt repräsentieren, da neue Therapien ja in erster Linie nicht einen (artifiziellen) Neutrophileneinstrom verhindern, sondern eine bereits etablierte Neutrophilie reduzieren sollen.

Trotzdem bietet das Phänomen einer ausgeprägten Atemwegsneutrophilie bei COPD, die durch nicht-invasive Methoden wie Sputuminduktion leicht und reproduzierbar quantifizierbar ist, eine Reihe von Vorteilen. Eigene Arbeiten und die anderer Autoren konnten belegen, dass die Sputumneutrophilie bei stabiler COPD auch über längere Zeiträume sehr gut reproduzierbar ist $[29,169]$. Dies ermöglicht es, z.B. die Sputumneutrophilie als Zielparameter für klinische Studien zu definieren. Basierend auf eigenen und anderen publizierten [43] Daten bezüglich der Variabilität von Sputumbefunden bei COPD benötigt man z.B. in einer klinischen Studie (Cross-over-Design) zur Demonstration einer mindestens 25\%igen Reduktion der Sputumneutrophilen (80\% Power, alpha 0,05 beidseitig) nur 15-20 Patienten [170].

In diesem Zusammenhang stellt sich allerdings die Frage, welche Reduktion einer Atemwegs-Neutrophilie erzielt werden muss, um auch mit einer klinisch relevanten Verbesserung einherzugehen. Die denkbar einfachste Art, diese Frage zu beantworten wäre die Forderung einer Reduktion der Sputumneutrophilen auf „Normalwerte“, d.h. einen Neutrophilenanteil von 5-30\% der Sputumgesamtzellzahl (gesunde Nichtraucher) [26,171-173]. Leider verbietet sich eine differenziertere Antwort auf diese Frage aufgrund fehlender Evidenz. Das Ausmaß einer therapeutisch angestrebten Neutrophilenreduktion dürfte zudem in Abhängigkeit von dem jeweils gewählten klinischen Zielparameter wie Symptomatik, Atemwegsobstruktion, Exazerbationshäufigkeit oder Erkrankungsprogress variieren. Während bei anderen entzündlichen Atemwegserkrankungen mit Neutrophilie wie zystischer Fibrose oder obliterativer Bronchiolitis nach Lungentransplantation Überlebenszeit oder progressionsfreies Überleben valide und aussagekräftige klinische Zielparameter darstellen, sind diese bei COPD oder gar Asthma bronchiale nur von untergeordneter Bedeutung. Welche Auswirkung auf klinische Parameter könnte eine Reduktion neutrophiler Granulozyten in den Atemwegen betroffener COPD-Patienten also haben? Zweifelsfrei besteht bei COPD eine Korrelation von Atemwegsneutrophilie [40] bzw. Neutrophileninfiltration glatter Bronchialmuskelzellen [41] mit dem FEV . Zieht man jedoch in Betracht, dass die Atemwegsobstruktion bei COPD definitionsgemäß nur eingeschränkt reversibel ist, kann also kaum erhofft werden, dass eine Reduktion der Neutrophilie mit einer deutlichen Verbesserung der Lungenfunktion einhergeht. Infolgedessen ist es notwendig, andere klinische Zielparameter in Betracht zu ziehen.
Welche Parameter können dies nun sein? (1) Stanescu u. Mitarb. beschrieben eine Korrelation zwischen Atemwegsneutrophilie und dem beschleunigten Verlust an Lungenfunktion $\left(\mathrm{FEV}_{1}\right)$ bei einer Gruppe von COPD-Patienten [174]. Dabei zeigten sie, dass eine Vermehrung der Neutrophilen um ca. 30\% den jährlichen Verlust an $\mathrm{FEV}_{1}$ um mindestens $10 \mathrm{ml}$ gegenüber Patienten mit niedrigerer Neutrophilenzahl steigerte. Diese Ergebnisse lassen den Schluss zu, dass ein therapeutische Reduktion der neutrophilen Entzündung in der Lage sein sollte, den progredienten Verlust an Lungenfunktion bei COPD-Patienten langfristig aufzuhalten. Auf diesen Endpunkt ausgerichtete Studien sind jedoch extrem kostenintensiv, basieren auf großen Patientenzahlen und sollten sich über mindestens zwei Jahre Dauer erstrecken. Daraus wird deutlich, dass die Wahl dieses Endpunktes zwar valide sein mag, aber selbst für große Arzneimittelhersteller ein schwer kalkulierbares finanzielles Risiko darstellen dürfte.

(2) Es wird allgemein angenommen, dass ein Zusammenhang zwischen Atemwegsentzündung und COPD-Exazerbationen besteht, insofern auch die Exazerbationsrate als aussagekräftiger Zielparameter bei klinischen Studien mit anti-entzündlichen Substanzen bei COPD anerkannt wird. Qiu u. Mitarb. beschrieben kürzlich eine vermehrte Neutrophilie in bronchialen Biopsien von COPD-Patienten während einer akuten Exazerbation [20]. Allerdings fand man in einer anderen COPD-Kohorte bezüglich der Sputumneutrophilen keine Unterschiede während akuter Exazerbationen oder in einer stabilen Phase der Erkrankung [11]. In dieser Studie war eine erhöhte Sputumneutrophilenzahl zudem nicht prädiktiv für die Exazerbationshäufigkeit. Ähnliche Ergebnisse fanden auch Gompertz u. Mitarb. [95], die nachwiesen, dass man COPD-Patienten mit häufigen Exazerbationen nicht anhand ihres Entzündungsmusters in den Atemwegen von Patienten mit seltenen Exazerbationen unterscheiden kann. Wenngleich also die Exazerbationsrate prinzipiell als der gegenwärtig valideste und praktikabelste Endpunkt für COPD-Studien mit antiinflammatorischen Substanzen angesehen werden kann, ist die Assoziation zwischen Sputumneutrophilie und Exazerbationshäufigkeit bei COPD bislang alles andere als konsistent.

Angesichts der unsicheren Datenlage zum Zusammenhang zwischen Sputumneutrophilie und etablierten klinischen Parametern bleibt es daher weitgehend spekulativ festzulegen, welche Neutrophilenreduktion ein neuer Therapieansatz bewerkstelligen sollte, um mit hinreichender Wahrscheinlichkeit auch einen substanziellen klinischen Effekt bewirken zu können. Dies ist jedoch Grundlage für eine weitere klinische Entwicklung dieser Therapien.

Sowohl in Therapiestudien mit COPD-Patienten als auch Asthmatikern sind wiederholt inflammatorische Surrogatmarker als sekundäre Zielparameter untersucht worden $[42,43,73,76,175,176]$. Allerdings konnte bislang in keiner Studie überzeugend dargelegt werden, dass die Bestimmung löslicher Entzündungsmediatoren im Sputum oder der BAL über die einfache Differenzialzytologie hinausgehende klinische Informationen liefert. Eine Ausnahme stellt allenfalls eine Studie von Bhowmik u. Mitarb. dar [11], die zeigen konnten, dass durch die zusätzliche Bestimmung von IL-6 und IL-8 im Sputumüberstand die Exazerbationshäufigkeit bei COPD-Patienten präziser voraus gesagt werden konnte als durch die alleinige Differenzial- 


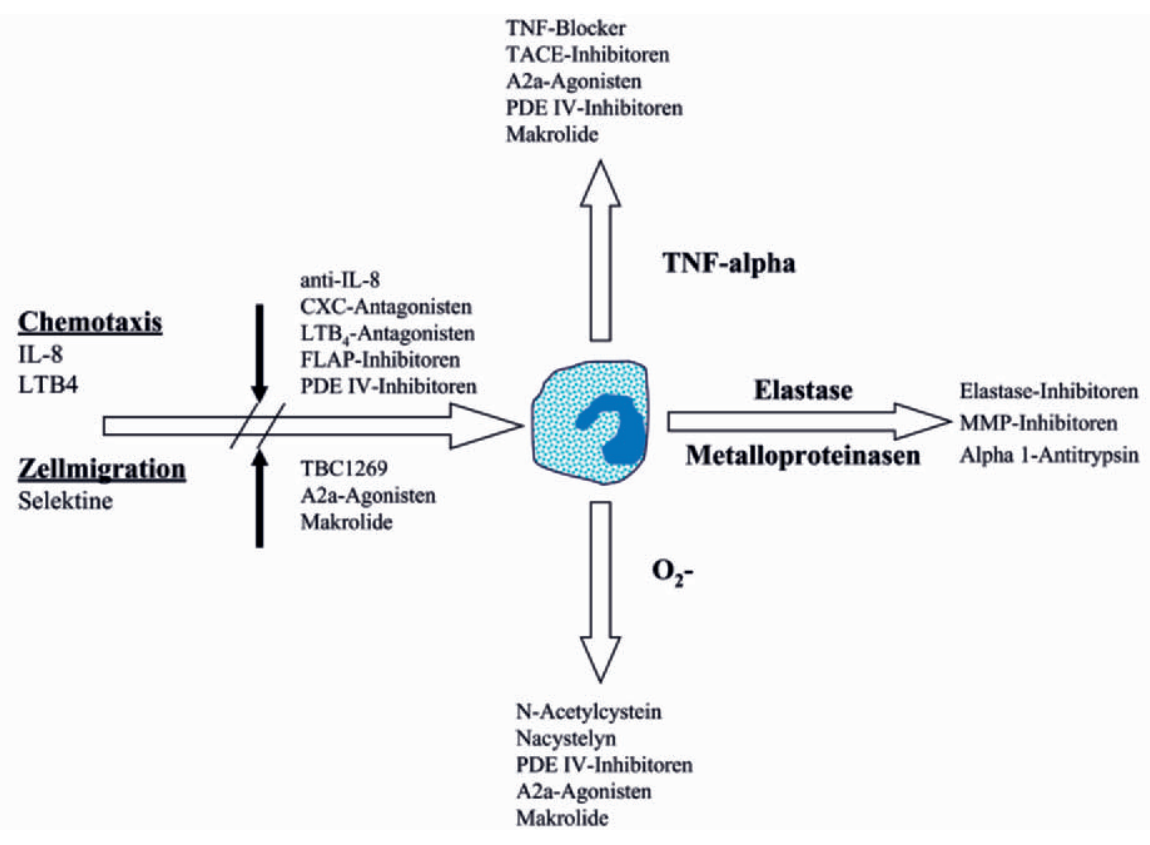

Abb. 1 Neutrophile Effektormechanismen mit pathogenetischer Bedeutung für die COPD und daraus abgeleitete Therapieansätze

zytologie. Bislang kann daher der unkritische Einsatz von z.B. Sputumsurrogatmarkern als primäre oder auch sekundäre Zielparameter in klinischen Studien nicht empfohlen werden. Dies gilt auch für andere Surrogatmarker der neutrophilen Entzündung. Ein solcher Marker könnte z.B. auch das exhalierte Stickstoffmonoxid (eNO) sein. eNO ist bei COPD [177], obliterativer Bronchiolitis nach Lungentransplantation und idiopathischer Lungenfibrose [178] erhöht und bei diesen Erkrankungen positiv mit der neutrophilen Entzündung korreliert. Allerdings liegen die hier gemessenen eNO-Werte deutlich niedriger als bei Asthmatikern und sind schlechter reproduzierbar. Somit brauchte man für klinische Studien eine deutlich höhere Patientenzahl. Auch hier ist jedoch völlig offen, ob eine Reduktion des eNO auch von klinischer Relevanz ist.

Eine weitere Methode zur Beurteilung des mit neutrophiler Atemwegsentzündung assoziierten oxidativen Stresses stellt die Atemkondensatmessung dar. Hier können verschiedene direkte und indirekte Marker einer oxidativen Belastung wie $\mathrm{H}_{2} \mathrm{O}_{2}$, 8-Isoprostan, Glutathion, Nitrosothiole, aber auch proinflammatorische Mediatoren wie Leukotriene und Zytokine relativ einfach und mit akzeptabler Reproduzierbarkeit bestimmt werden $[179,180]$. So konnte kürzlich in zwei Langzeitstudien mit COPDPatienten gezeigt werden, dass die orale Gabe von NAC zu einer Reduktion von $\mathrm{H}_{2} \mathrm{O}_{2}$ im Atemkondensat führt $[159,160]$. Unklar ist jedoch, ob dieser Effekt auch mit einer Verbesserung der zellulären Inflammation einhergeht. Zahlreiche weitere Publikationen unterstreichen das Potenzial der Methode bei Asthma bronchiale, COPD, zytischer Fibrose, aber auch interstitiellen Lungenerkrankungen und Monitoring nach Lungentransplantation. Allerdings bestehen trotz dieser vielversprechenden Ergebnisse derzeit noch zahlreiche offene methodische Fragen, die vor einem routinemäßigen Einsatz des Atemkondensates in klinischen Studien geklärt werden müssen.

\section{Kritische Zusammenfassung und Ausblick}

In den letzten Jahren sind außerordentliche Anstrengungen unternommen worden, um die Rolle neutrophiler Entzündungsvorgänge in der Pathogenese chronisch-entzündlicher Atemwegserkrankungen, insbesondere COPD, näher zu beleuchten. Es ist das Resultat dieser Bemühungen, dass wichtige Zielmediatoren für zukünftige Therapiestrategien identifiziert und spezifische Inhibitoren entwickelt werden konnten (Abb.1). Diese Untersuchungen führten zu einem enormen Wissenszuwachs und besseren Verständnis der inflammatorischen Pathogenese der COPD. Im Hinblick auf Therapieansätze, die eine Reduktion der neutrophilen Entzündung zum Ziel haben, scheint jedoch ein Dilemma zwischen angestrebter Wirksamkeit und bestmöglicher Verträglichkeit zu bestehen. Einerseits kann die hochselektive und spezifische Antagonisierung einzelner „Schlüssel“-Mediatoren sich als verträglich, aber unwirksam erweisen, andererseits trägt eine eher breit gefächerte Suppression der Neutrophilen-Kaskade auch zumindest theoretisch ein erhebliches Risikopotenzial in sich. Studien an „knock-out“-Mäusen [181] z.B. belegen, dass eine therapeutische Inhibition neutrophiler Abwehrmechanismen zu schweren, systemischen Infektionen führen kann. Auch vermehrte klinische Fallberichte zu Infektionen unter TNF-Blockade bei Patienten mit rheumatoider Arthritis sollten zur Vorsicht vor einem breiten und unkritischen Einsatz derartiger Substanzen bei chronisch-entzündlichen Atemwegserkrankungen mahnen, da insbesondere die Rolle bakterieller Kolonisation bzw. chronischer Infektion bei COPD noch nicht abschließend geklärt ist.

Aktuell überwiegt hinsichtlich des Einsatzes anti-neutrophiler Therapien bei COPD eindeutig die Zahl offener Fragen gegenüber expliziten Antworten. Wie in den meisten biologischen Systemen unterliegt der Prozess der Neutrophilenrekrutierung und -aktivierung einer großen Redundanz. Daher ist es unwahrscheinlich, dass die Antagonisierung einzelner Zielmoleküle mit signifikanten klinischen Effekten einhergeht. Dagegen besteht 
für die systemische Applikation von Substanzen mit breiter antineutrophiler Wirkung das Risiko generalisierter Infektionen, ohne dass ein positiver Effekt auf die Entzündung der COPD garantiert wäre. In einer unkontrollierten Observationsstudie an COPD-Patienten, die sich aufgrund einer malignen Erkrankung einer Neutrophilen-depletierenden Chemotherapie unterzogen, konnten wir nachweisen, dass die neutrophile Atemwegsentzündung dieser Patienten zumindest kurzfristig selbst durch eine systemische Chemotherapie unbeeinflusst war [182]. Vor diesem Hintergrund erscheinen auch die zahlreichen negative Resultate aus klinischen Studien mit oralen Therapieansätzen nicht überraschend. Erfreulicherweise bieten pulmonale Erkrankungen immer auch die Möglichkeit einer lokalen Applikation, d.h. Inhalation von Wirkstoffen. Dies ermöglicht die therapeutische Applikation höherer Wirkstoffkonzentrationen an den Ort der Entzündung bei gleichzeitiger Reduktion potenzieller systemischer Nebenwirkungen. Daher erscheint es logisch, den inhalativen Applikationsweg als Therapieansatz der ersten Wahl für antineutrophile Therapeutika zu betrachten.

Von den in diesem Übersichtsartikel diskutierten neuen Ansätzen befinden sich die PDE-IV-Inhibitoren zweifellos im fortgeschrittensten Entwicklungsstadium. Trotz einiger Rückschläge in der klinischen Entwicklung einzelner Substanzen kann man davon ausgehen, dass zumindest ein Vertreter dieser Klasse in den nächsten Jahren die Marktzulassung erreichen wird. Insbesondere klinische Langzeitergebnisse sowie Vollpublikationen zu Exazerbationen, Progression der Atemwegsobstruktion, Symptomatik und Lebensqualität sowie Verträglichkeit bei COPD werden mit Spannung erwartet. Die überwiegend negativen Resultate der klinischen Langzeitstudie mit NAC bei COPD und die erwartete Publikation der Langzeitstudie mit NAC bei Lungenfibrose werden dazu beitragen, die zukünftige Rolle von Antioxidanzien in der Therapie von pulmonalen Erkrankungen genauer zu definieren. Es bleibt zu hoffen, dass in Zukunft weitere Therapieansätze entwickelt werden, die die zahlreichen Facetten der durch Neutrophile vermittelten chronischen Atemwegsentzündung wirksamer bekämpfen können.

In Anbetracht der Vielzahl wissenschaftlicher Publikationen zu neuartigen Therapieansätzen auf dem Gebiet entzündlicher Atemwegserkrankungen erhebt dieser Übersichtsartikel keinen Anspruch auf Vollständigkeit. Es gibt zahlreiche weitere „emerging therapies" die z.T. auch auf die neutrophile Entzündung zielen (MAP-Kinase-Inhibitoren, Zytokine, monoklonale Antikörper, neue Mukolytika etc.). Für viele solcher Ansätze existieren jedoch bislang weder tierexperimentelle Daten im Erkrankungsmodell noch klinische Erfahrungen. Der Schwerpunkt unseres Übersichtsartikel lag daher auf Substanzen, für die zumindest erste Daten aus klinischen Studien vorliegen. Für alle gegenwärtigen oder zukünftigen antiinflammatorischen Therapeutika der COPD dürfte jedoch die Wahl geeigneter Zielparameter in klinischen Studien von entscheidender Bedeutung sein.
${ }^{1}$ Stockley RA. Neutrophils and the pathogenesis of COPD. Chest 2002; 121: $151 \mathrm{~S}-155 \mathrm{~S}$

2 Thurlbeck WM. Pathology of chronic obstructive pulmonary disease. Clin Chest Med 1990; 11: 389-404

${ }^{3}$ Di Stefano A, Capelli A, Lusuardi M et al. Severity of airflow limitiation is associated with severity of airway inflammation in smokers. Am J Respir Crit Care Med 1998; 158: 1277-1285

${ }^{4}$ Burge PS, Calverley PMA, Jones PW et al. Randomised double blind, placebo controlled study of fluticasone propionate in patients with moderate to severe chronic obstructive pulmonary diease: the ISOLDE trial. Br Med J 2000; 320: 1297-1303

${ }^{5}$ Paggiaro PL, Dahle R, Barman I et al. Multicenter randomised placebo-controlled trial of inhaled fluticasone proprionate in patients with chronic obstructive pulmonary disease. Lancet 1998; 351: $773-780$

${ }^{6}$ Vestbo J, Sorensen TIA, Lange P et al. Long-term effect of inhaled budesonide in mild and moderate chronic obstructive pulmonary disease: a randomised controlled trial. Lancet 1999; 353: 1819-1823

${ }^{7}$ Lung Health Study Group. Effect of Inhaled Triamcinolone on the Decline in Pulmonary Function in Chronic Obstructive Pulmonary Disease. N Engl J Med 2000; 343: 1902 - 1909

${ }^{8}$ Anthonisen NR, Connett JE, Kiley JP et al. Effects of smoking intervention and the use of an inhaled anticholinergic bronchodilator on the rate of decline of $\mathrm{FEV}_{1}$. The lung health study. JAMA 1994; 272: $1497-1505$

${ }^{9}$ Rutgers SR, Postma DS, ten Hacken NH et al. Ongoing airway inflammation in patients with COPD who do not currently smoke. Thorax 200; 55: $12-18$

${ }^{10}$ Turato G, Di Stefano A, Maestrelli P et al. Effect of smoking cessation on airway inflammation in chronic bronchitis. Am J Respir Crit Care Med 1995; 152: $1262-1267$

${ }^{11}$ Bhowmik A, Seemungal TAR, Sapsford RJ et al. Relation of sputum inflammatory markers to symptoms and lung function changes in COPD exacerbations. Thorax 2000; 55: 114-120

${ }^{12}$ Stockley RA. Neutrophils and protease/antiprotease imbalance. Am J Respir Crit Care Med 1999; 160: S49-S52

${ }^{13}$ Nadel JA. Role of neutrophil elastase in hypersecretion during COPD exacerbations, and proposed therapies. Chest 2000; 117: 386S-389S

${ }^{14}$ Vestbo J, Prescott E, Lange DP. Association of chronic mucus hypersecretion with FEV1 decline and chronic obstructive pulmonary disease morbidity. Am J Respir Crit Care Med 1996; 153: 1530-1535

${ }^{15}$ Maestrelli P, Calcagni PG, Saetta M et al. Integrin upregulation on sputum neutrophils in smokers with chronic airway obstruction. Am J Respir Crit Care Med 1996; 154: 1296 - 1300

${ }^{16}$ Noguera A, Busquets X, Sauleda J et al. Expression of adhesion molecules and $G$ proteins in circulating neutrophils in chronic obstructive pulmonary disease. Am J Respir Crit Care Med 1998; 158: 1664 - 1668

${ }^{17}$ Noguera A, Batle S, Miralles C et al. Enhanced neutrophil response in chronic obstructive pulmonary disease. Thorax 2001; 56: 432 - 437

${ }^{18}$ Burnett D, Chamba A, Hill SL et al. Neutrophils from subjects with chronic obstructive lung disease show enhanced chemotaxis and extracellular proteolysis. Lancet 1987; II (8567): 1043 - 1046

${ }^{19}$ Aaron SD, Angel JB, Lunau M et al. Granulocyte Inflammatory Markers and Airway Infection during Acute Exacerbation of Chronic Obstructive Pulmonary Disease. Am J Respir Crit Care Med 2001; 163: $349-355$

${ }^{20}$ Qiu Y, Zhu J, Bandi V et al. Biopsy neutrophilia, neutrophil chemokine and receptor gene expression in severe exacerbations of chronic obstructive pulmonary disease. Am J Respir Crit Care Med 2003; 168: $968-975$

${ }^{21}$ Yamamoto C, Yoneda T, Yoshikawa M et al. Airway inflammation in COPD assessed by sputum levels of interleukin-8. Chest 1997; 112: 505- 510

22 Traves SL, Culpitt SV, Russell RE et al. Increased levels of the chemokines GROalpha and MCP-1 in sputum samples from patients with COPD. Thorax 2002; 57: 590-595

${ }^{23}$ Keatings VM, Collins PD, Scott DM et al. Differences in interleukin-8 and tumor necrosis factor- $\mathrm{a}$ in induced sputum from patients with chronic obstructive pulmonary disease or asthma. Am J Respir Crit Care Med 1996; 153: 530-534 
${ }^{24}$ Hill AT, Bayley D, Stockley RA. The interrelationship of sputum inflammatory markers in patients with chronic bronchitis. Am J Respir Crit Care Med 1999; 160: 893-898

${ }^{25}$ Lim SN, Roche N, Oliver BG et al. Balance of matrix metalloprotease-9 and tissue inhibitor of metalloprotease- 1 from alveolar macrophages in cigarette smokers. Regulation By interleukin-10. Am J Respir Crit Care Med 2000; 162: 1355-1360

${ }^{26}$ Beeh KM, Beier J, Kornmann O et al. Sputum matrixmetalloproteinase-9, tissue inhibitor of metalloproteinase-1, and their molar ratio in patients with chronic obstructive pulmonary disease, idiopathic pulmonary fibrosis and healthy subjects. Respir Med 2003; 97: 634 -639

${ }^{27}$ Finlay GA, Russell KJ, McMahon KJ et al. Elevated levels of matrix metalloproteinases in bronchoalveolar lavage fluid of emphysematous patients. Thorax 1997; 52: $502-506$

${ }^{28}$ Keatings VM, Barnes PJ. Granulocyte activation markers in induced sputum: comparison between chronic obstructive pulmonary disease, asthma, and normal subjects. Am J Respir Crit Care Med 1997; 155: $449-453$

${ }^{29}$ Beeh KM, Beier J, Kornmann O et al. Long-term repeatability of induced sputum inflammatory markers in stable, moderately severe COPD. Chest 2003; 123: $778-783$

${ }^{30}$ Ichinose $\mathrm{M}$, Sugiura $\mathrm{H}$, Yamagata $\mathrm{S}$ et al. Increase in reactive nitrogen species production in chronic obstructive pulmonary disease airways. Am J Respir Crit Care Med 2000; 162: 701 - 706

${ }^{31}$ Corradi M, Montuschi P, Donnelly LE et al. Increased nitrosothiols in exhaled breath condensate in inflammatory airway diseases. Am J Respir Crit Care Med 2001; 163: 854-858

32 Kanazawa HS, Shiraishi S, Hirata K et al. Imbalance between levels of nitrogen oxides and peroxynitrite inhibitory activity in chronic obstructive pulmonary disease. Thorax 2003; 58: 106-109

${ }^{33}$ Beeh KM, Beier J, Koppenhoefer $\mathrm{N}$ et al. Increased glutathione disulfide and nitrosothiols in COPD sputum supernatant. Chest 2004; 126 : $1116-1122$

${ }^{34}$ Montuschi P, Collins JV, Ciabattoni G et al. Exhaled 8-isoprostane as an in vivo biomarker of lung oxidative stress in patients with COPD and healthy smokers. Am J Respir Crit Care Med 2000; 162: $1175-1177$

${ }^{35}$ Morrison D, Rahman I, Lannan S et al. Epithelial permeability, inflammation, and oxidant stress in the air spaces of smokers. Am J Respir Crit Care Med 1999; 159: 473-479

${ }^{36}$ McNulty CA, Symon FA, Wardlaw AJ. Characterization of the integrin and activation steps mediating human eosinophil and neutrophil adhesion to chronically inflamed airway endothelium. Am J Respir Cell Mol Biol 1999; 20: 1251 - 1259

${ }^{37}$ Adams DH, Lloyd AR. Chemokines: leucocyte recruitment and activation cytokines. Lancet 1997; 349: 490-495

${ }^{38}$ Selby C, Drost E, Lannan S et al. Neutrophil retention in the lungs of patients with chronic obstructive pulmonary disease. Am Rev Respir Dis 1991; 143: 1359-1364

${ }^{39}$ Lams BE, Sousa AR, Rees PJ et al. Immunopathology of the Small-Airway Submucosa in Smokers with and without Chronic Obstructive Pulmonary Disease. Am J Respir Crit Care Med 1998; 158: 1518 - 1523

${ }^{40}$ Pilette C, Godding V, Kiss R et al. Reduced epithelial expression of secretory component in small airways correlates with airflow obstruction in chronic obstructive pulmonary disease. Am J Respir Crit Care Med 2001; 163: 185-194

${ }^{41}$ Baraldo S, Turato G, Badin C et al. Neutrophilic infiltration within the airway smooth muscle in patients with COPD. Thorax 2004; 59: $308-312$

${ }^{42}$ Keatings VM, Jatakanon A, Worsdell YM et al. Effects of inhaled and oral glucocorticosteroids on inflammatory indices in asthma and COPD. Am J Respir Crit Care Med 1997; 155: 542 - 548

${ }^{43}$ Culpitt SV, Maziak W, Loukidis S et al. Effect of high dose inhaled steroid on cells, cytokines, and proteases in induced sputum in chronic obstructive pulmonary disease. Am J Respir Crit Care Med 1999; 160: $1635-1639$

${ }^{44}$ Gonfalonieri M, Mainardi E, Della Porta R et al. Inhaled corticosteroids reduce neutrophilic bronchial inflammation in patients with chronic obstructive pulmonary disease. Thorax 1998; 53: 583-585

45 Yildiz F, Kaur AC, Ilgazi A et al. Inhaled corticosteroids may reduce neutrophilic inflammation in patients with stable chronic obstructive pulmonary disease. Respiration 2000; 67: 71 - 76

${ }^{46}$ Barnes PJ, Ito K, Adcock IM. Corticosteroid resistance in chronic obstructive pulmonary disease: inactivation of histone deacetylase. Lancet 2004; 363: $731-733$
${ }^{47}$ GOLD Executive Summary. Global strategy for the diagnosis, management, and prevention of chronic obstructive pulmonary disease: 2003 update. NIH Publication, 2003: 1-42

${ }^{48}$ Calotta F, Re F, Polentarutti N et al. Modulation of granulocyte survival and programmed cell death by cytokines and bacterial products. Blood 1992; 80: 2012 - 2020

${ }^{49}$ Drost EM, MacNee W. Potential role of IL-8, platelet-activating factor and TNF-alpha in the sequestration of neutrophils in the lung: effects on neutrophil deformability, adhesion receptor expression, and chemotaxis. Eur J Immunol 2002; 32: 393 - 403

50 John M, Au BT, Jose PJ et al. Expression and release of interleukin- 8 by human airway smooth muscle cells: inhibition by Th-2-cytokines and corticosteroids. American Review of Respiratory and Cellular and Molecular Biology 1998; 18 (1): 84-90

${ }^{51}$ Beeh KM, Kornmann O, Buhl R et al. Neutrophil chemotactic activity of sputum from patients with COPD: role of interleukin 8 and leukotriene B4. Chest 2003; 123: 1240-1247

52 Tanino M, Betsuyaku T, Takeyabu K et al. Increased levels of interleukin-8 in BAL fluid from smokers susceptible to pulmonary emphysema. Thorax 2002; 57: 405-411

${ }^{53}$ Gibson PG, Simpson JL, Saltos N. Heterogeneity of airway inflammation in persistent asthma: evidence of neutrophilic inflammation and increased sputum interleukin-8. Chest 2001; 119: 1329-1336

${ }^{54}$ Jatakanon A, Uasuf C, Maziak W et al. Neutrophilic inflammation in severe persistent asthma. Am J Respir Crit Care Med 1999; 160: $1532-1539$

${ }^{55}$ Richman-Eisenstat JB, Jorens PG, Hebert CA et al. Interleukin-8: an important chemoattractant in sputum of patients with chronic inflammatory airway diseases. Am J Physiol 1993; 264: L413 - L418

${ }^{56}$ Beeh KM, Beier J, Kornmann O et al. Neutrophilic inflammation in induced sputum of patients with idiopathic pulmonary fibrosis. Sarc Vasc Diff Lung Dis 2003; 20: 138-143

${ }^{57}$ DiGiovine B, Lynch JP, Martinez FJ et al. 1996. Bronchoalveolar lavage neutrophilia is associated with obliterative bronchiolitis after lung transplantation: role of IL-8. J Immunol 1996; 157: 4194-4202

${ }^{58}$ Feldmann M, Brennan FM, Maini RN. Role of cytokines in rheumatoid arthritis. Annu Rev Immunol 1996; 14: $397-440$

${ }^{59}$ Yuan A, Yang PC, Yu CJ et al. Interleukin-8 messenger ribonucleic acid expression correlates with tumor progression, tumor angiogenesis, patient survival, and timing of relapse in non-small-cell lung cancer. Am J Respir Crit Care Med 2000; 162: 1957-1963

${ }^{60}$ Yuan A, Yu CJ, Luh KT et al. Aberrant p53 expression correlates with expression of vascular endothelial growth factor mRNA and interleukin-8 mRNA and neoangiogenesis in non-small-cell lung cancer. J Clin Oncol 2002; 20: 900-910

${ }^{61}$ Huang S, Mills L, Mian B et al. Fully humanized neutralizing antibodies to interleukin-8 (ABX-IL8) inhibit angiogenesis, tumor growth, and metastases of human melanoma. Am J Pathol 2002; 161: $125-134$

62 Yang XD, Corvalan JR, Wang P et al. 1999. Fully human anti-interleukin-8 monoclonal antibodies: potential therapeutics for the treatment of inflammatory disease states. J Leukoc Biol 1999; 66: $401-410$

${ }^{63}$ Mahler DA, Huang SL, Tabrizi M et al. Efficacy and Safety of a Monoclonal Antibody Recognizing Interleukin-8 in COPD: A Pilot Study. Chest 2004; 126: 926-934

${ }^{64} \mathrm{McC}$ ll SR, Clark-Lewis I. Inhibition of murine neutrophil recruitment in vivo by CXC chemokine receptor antagonists. J Immunol 1999; 163: $2829-2835$

${ }^{65}$ White JR, Lee JM, Young PR et al. Identification of a potent, selective non-peptide CXCR2 antagonist that inhibits interleukin-8-induced neutrophil migration. J Biol Chem 1998; 273: 10095 - 10098

${ }^{66}$ Crooks SW, Stockley RA. Leukotriene B4. Int J Biochem Cell Biol 1998; 30: 173-178

${ }^{67}$ Martin TR, Pistorese BP, Chi EY et al. Effects of leukotriene B4 in the human lung: Recruitment of neutrophils into the alveolar spaces without a change in protein permeability. J Clin Invest 1989; 84: $1609-1619$

${ }^{68}$ Seggev JS, Thornton WH, Edes TE. Serum leukotriene B4 levels in patients with obstructive pulmonary disease. Chest 1991; 99: 289-291

69 Wardlaw AJ, Hay H, Cromwell O et al. Leukotrienes, LTC4 and LTB4, in bronchoalveolar lavage in bronchial asthma and other respiratory diseases. J Allergy Clin Immunol 1989; 84: 19-26

70 Woolhouse IS, Bayley DL, Stockley RA. Sputum chemotactic activity in chronic obstructive pulmonary disease: effect of a1-antitrypsin 
deficiency and the role of leukotriene B4 and interleukin 8. Thorax 2002; 57: 709-714

${ }^{71}$ Biernacki WA, Kharitonov SA, Barnes PJ. Increased leukotriene B4 and 8 -isoprostane in exhaled breath condensate of patients with exacerbations of COPD. Thorax 2003; 58: 294-298

${ }^{72}$ Lee E, Lindo T, Jackson $\mathrm{N}$ et al. Reversal of human neutrophil survival by leukotriene B4 receptor blockade and 5-lipoxygenase activating protein inhibitors. Am J Respir Crit Care Med 1999; 160: 2079-2085

${ }^{73}$ Gompertz S, Stockley RA. A randomized, placebo-controlled trial of a leukotriene synthesis inhibitor in patients with COPD. Chest 2002; 122: $289-294$

${ }^{74}$ Silbaugh SA, Stengel PW, Cockerham SL et al. Pharmacologic actions of the second generation leukotriene B4 receptor antagonist LY29311: in vivo pulmonary studies. Naunyn Schmiedebergs Arch Pharmacol 2000; 361: 397 - 404

75 Evans DJ, Barnes PJ, Spaethe SM et al. Effect of a leukotriene B4 receptor antagonist, LY293111, on allergen induced responses in asthma. Thorax 1996; 51: 1178 - 1184

${ }^{76}$ Groenke L, Beeh KM, Wang JH et al. LTB 019A, a leukotriene B4 receptor antagonist, has no effect on the levels of neutrophils, MPO, IL-8 and TNF-alpha in induced sputum of patients with COPD. Am J Respir Crit Care Med 2002; 165: A225

77 Dang B, Wiehler S, Patel KD. Increased PSGL-1 expression on granulocytes from allergic asthmatic subjects results in enhanced leukocyte recruitment under flow conditions. J Leukoc Biol 2002; 72: 702 - 710

${ }^{78}$ Lin SJ, Chang LY, Yan DC et al. Decreased intercellular adhesion molecule-1 (CD54) and L-selectin (CD62L) expression on peripheral blood natural killer cells in asthmatic children with acute exacerbation. $\mathrm{Al}-$ lergy 2003; 58: $67-71$

${ }^{79}$ Pettersen CA, Adler KB. Airways inflammation and COPD. Epithelialneutrophil interactions. Chest 2002; 121: 142S-150S

${ }^{80}$ Abraham WM, Ahmed A, Sabater JR et al. Selectin blockade prevents antigen-induced late bronchial responses and airway hyperresponsiveness in allergic sheep. Am J Respir Crit Care Med 1999; 159: $1205-1214$

${ }^{81}$ Sanctis GT de, Wolyniec WW, Green FH et al. 1997. Reduction of allergic airway responses in P-selectin-deficient mice. J Appl Physiol 1997; 83: $681-687$

${ }^{82}$ Lukacs NW, John A, Berlin A et al. E- and P-selectins are essential for the development of cockroach allergen-induced airway responses. J Immunol 2002; 169: 2120-2125

${ }^{83}$ Radi ZA, Brodgen KA, Dixon RA et al. A selectin inhibitor decreases neutrophil infiltration during acute mannheimia haemolytica pneumonia. Vet Pathol 2002; 39: 697-705

${ }^{84}$ Kogan TP, Dupre B, Bui H et al. Novel synthetic inhibitors of selectinmediated cell adhesion: synthesis of 1,6-bis[3-(3-carboxymethylphenyl)-4-(2-alpha-D- mannopyranosyloxy)phenyl]hexane (TBC1269). J Med Chem 1998; 41: 1099-1111

${ }^{85}$ Davenpeck KL, Berens KL, Dixon RA et al. Inhibition of adhesion of human neutrophils and eosinophils to P-selectin by the sialyl Lewis antagonist TBC1269: preferential activity against neutrophil adhesion in vitro. J Allergy Clin Immunol 2000; 105: 769- 775

${ }^{86}$ Avila PC, Boushey HA, Wong H et al. 2004. Effect of a single dose of the selectin inhibitor TBC1269 on early and late asthmatic responses. Clin Exp Allergy 2004; 34: 77-84

${ }^{87}$ Beeh KM, Beier J, Meyer M et al. Bimosiamose, an inhaled small-molecule pan-selectin antagonist, attenuates late asthmatic reactions following allergen challenge in mild asthmatics: A randomized, double-blind, placebo-controlled clinical cross-over-trial. Pulmonary Pharmacology and Therapeutics 2005: DOI: 10.1016/j.pubt.2005.07.004

${ }^{88} \mathrm{Hu}$ Y, Kiely JM, Szente BE et al. E-selectin-dependent signaling via the mitogen-activated protein kinase pathway in vascular endothelial cells. J Immunol 2000; 165: $2142-2148$

${ }^{89}$ Lorenzon P, Vedile E, Nardon E et al. Endothelial cell E- and P-Selectin and vascular cell adhesion molecule-1 function as signalling receptors. J Cell Biol 1998; 142: 1381 - 1391

${ }^{90}$ Laudanna C, Constantin G, Baron P et al. Sulfatides trigger increase of cytosolic free calcium and enhanced expression of tumor necrosis factor-alpha and interleukin-8 mRNA in human neutrophils. J Biol Chem 1994; 269: 4021-4026

${ }^{91}$ Bouma MG, Jeunhomme TM, Boyle DL et al. Adenosine inhibits neutrophil degranulation in activated human whole blood: involvement of adenosine A2 and A3 receptors. J Immunol 1997; 158: 5400-5408
${ }^{92}$ Fozard JR, Ellis KM, Villela Dantas MF et al. Effects of CGS 21680, a selective adenosine $\mathrm{A} 2 \mathrm{~A}$ receptor agonist, on allergic airways inflammation in the rat. Eur J Pharmacol 2002; 438: 183- 188

${ }^{93}$ Luijk B, Berge M van den, Kerstjens HAM et al. Effect of an inhaled adenosine A2A agonist on the allergen induced late asthmatic response. Eur Respir J 2003; 22: 204s - 204s

${ }^{94}$ Stockley RA. The role of proteinases in the pathogenesis of chronic bronchitis. Am J Respir Crit Care Med 1994; 150: S109-S113

${ }^{95}$ Gompertz S, Bayley DL, Hill SL et al. Relationship between airway inflammation and the frequency of exacerbations in patients with smoking related COPD. Thorax 2001; 56: 36-41

${ }^{96}$ Janoff A. Elastase and emphysema. Current assessment of the protease- antiprotease hypothesis. Am Rev Respir Dis 1985; 132: 417-433

${ }^{97}$ Carp H, Miller RF, Hoidal JR et al. Potential mechanism of emphysema: a1-proteinase inhibitor recovered from lungs of cigarette smokers contains oxidized methionine and has decreased elastase inhibitory capacity. Proc Natl Acad Sci USA 1982; 79: 2041 - 2045

98 Yokoyama E, Nambu Z, Uchiyama I et al. An emphysema model in rats treated intratracheally with elastase. Environ Res 1987; 42: 340 - 352

${ }^{99}$ Hautamaki RD, Kobayashi DK, Senior RM et al. Requirement for Macrophage Elastase for Cigarette Smoke-Induced Emphysema in Mice. Science 1997; 277: 2002 - 2004

100 Ohbayashi H. Neutrophil elastase inhibitors as treatment for COPD. Exp Opin Invest Drugs 2002; 11: 1-16

101 Tremblay GM, Janelle MF, Bourbonnais Y. Anti-inflammatory activity of neutrophil elastase inhibitors. Curr Opin Investig Drugs 2003; 4: $556-565$

102 Scuri M, Botvinnikova Y, Lauredo IT et al. Recombinant alpha-1 proteinase inhibitor blocks antigen- and mediator-induced airway responses in sheep. J Appl Physiol 2002; 93: 1900-1906

${ }^{103}$ Nagase H, Woessner JF. Matrix Metalloproteinases. J Biol Chem 1999; 274: $21491-21494$

104 Pugin J, Widmer MC, Kossodo S et al. Human neutrophils secrete gelatinase $B$ in vitro and in vivo in response to endotoxin and proinflammatory mediators. Am J Respir Cell Mol Biol 1999; 20: 458 - 464

105 Ray JM, Stetler-Stevenson WG. The role of matrix metalloproteases and their inhibitors in tumor invasion, metastasis and angiogenesis. Eur Respir J 1994; 7: 2062 - 2072

${ }^{106}$ Busse W, Elias J, Sheppard D et al. Airway remodeling and repair. Am J Respir Crit Care Med 1999; 160: 1035-1042

${ }^{107}$ Hoshino M, Nakamura Y, Sim JJ et al. Bronchial subepithelial fibrosis and expression of matrix metalloproteinase- 9 in asthmatic airway inflammation. J Allergy Clin Immunol 1998; 102: $783-788$

${ }^{108}$ Cataldo D, Bettiol J, Noel A et al. Matrix Metalloproteinase-9, but Not Tissue Inhibitor of Matrix Metalloproteinase-1, Increases in the Sputum From Allergic Asthmatic Patients After Allergen Challenge. Chest 2002; 122: 1553 - 1559

109 Tanaka H, Miyazaki N, Oashi KS et al. Sputum matrix metalloproteinase-9: tissue inhibitor of metalloproteinase-1 ratio in acute asthma. J Allergy Clin Immunol 2000; 105: 900-905

${ }^{110}$ Beeh KM, Beier J, Kornmann O et al. Sputum levels of Matrixmetalloproteinase-9, Tissue Inhibitor of Metalloproteinase-1, and their ratio correlate with airway obstruction in lung transplant recipients: relation to tumor necrosis factor-alpha and interleukin 10. J Heart Lung Transplant 2001; 20: 1144-1151

111 Schwingshackl A, Duszyk M, Brown N et al. Human eosinophils release matrix metalloproteinase-9 on stimulation with TNF-alpha. J Allergy Clin Immunol 1999; 104: 983-989

112 Zhang Y, McCluskey K, Fujii K et al. Differential regulation of monocyte matrix metalloproteinase and TIMP-1 production by TNF-alpha, granulocyte-macrophage CSF, and IL-1 beta through prostaglandindependent and -independent mechanisms. J Immunol 1998; 161: $3071-3076$

113 Meisser A, Chardonnens D, Campana A et al. Effects of tumour necrosis factor-alpha, interleukin-1 alpha, macrophage colony stimulating factor and transforming growth factor beta on trophoblastic matrix metalloproteinases. Mol Hum Reprod 1999; 5: 252-260

114 Bosse M, Chakir J, Rouabhia M et al. Serum matrix metalloproteinase-9: Tissue inhibitor of metalloproteinase- 1 ratio correlates with steroid responsiveness in moderate to severe asthma. Am J Respir Crit Care Med 1999; 159: 596-602

115 Quirt I, Bodurth A, Lohmann R et al. Phase II study of marimastat (BB-2516) in malignant melanoma: a clinical and tumor biopsy study of the National Cancer Institute of Canada Clinical Trial Groups. Invest New Drugs 2002; 20: $431-437$ 
116 Reimold AM. New indications for treatment of chronic inflammation by TNF-alpha blockade. Am J Med Sci 2003; 325: 75-92

117 Kuschner WG, D’Alessandro A, Wong $\mathrm{H}$ et al. Dose-dependent cigarette smoking-related inflammatory response in healthy adults. Eur Respir J 1996; 9: 1989-1994

118 Dubar V, Gosset $\mathrm{P}$, Aerts $\mathrm{C}$ et al. In vitro acute effects of tobacco smoke on tumor necrosis factor-alpha and interleukin- 6 production by alveolar macrophages. Exp Lung Res 1993; 19: 345 - 359

119 Huang SL, Su CH, Chang SC. Tumor necrosis factor-alpha gene polymorphism in chronic bronchitis. Am J Respir Crit Care Med 1997; 156: $1436-1439$

${ }^{120}$ Gan WQ Man SF, Senthilselvan A et al. Association between chronic obstructive pulmonary disease and systemic inflammation: a systemic review and a meta-analysis. Thorax 2004; 59: 574-580

${ }^{121}$ Brown SL, Greene MH, Gershon SK et al. Tumor necrosis factor antagonist therapy and lymphoma development: twenty-six cases reported to the Food and Drug Administration. Arthritis Rheum 2002; 46: $3151-3158$

122 Weisman $\mathrm{MH}$. What are the risks of biologic therapy in rheumatoid arthritis? An update on safety. J Rheumatol 2002; 65: S33-S38

123 Vaart H van der, Koeter GH, Postma DS et al. First Study of Infliximab Treatment in Patients with Chronic Obstructive Pulmonary Disease. Am J Respir Crit Care Med 2005; 172: 465-469

${ }^{124}$ Trifilieff A, Walker C, Keller T et al. Pharmacological profile of PKF242-484 and PKF241-466, novel dual inhibitors of TNF-\{alpha\} converting enzyme and matrix metalloproteinases, in models of airway inflammation. Br J Pharmacol 2002; 135: 1655-1664

125 Reid P. Roflumilast Altana Pharma. Curr Opin Investig Drugs 2002; 3: $1165-1170$

${ }^{126}$ Sturton G, Fitzgerald M. Phosphodiesterase 4 inhibitors for the treatment of COPD. Chest 2002; 121: 192S-196S

${ }^{127}$ Karlsson JA, Souness J, Webber S et al. Anti-inflammatory effects of the novel phosphodiesterase IV inhibitor RP 73 401. Int Arch Allergy Immunol 1995; 107: 425-426

${ }^{128}$ Hatzelmann A, Schudt C. Anti-inflammatory and immunomodulatory potential of the novel PDE4 inhibitor roflumilast in vitro. J Pharmacol Exp Ther 2001; 297: 267-279

${ }^{129}$ Bundschuh DS, Eltze M, Barsig J et al. In vivo efficacy in airway disease models of roflumilast, a novel orally active PDE4 inhibitor. J Pharmacol Exp Ther 2001; 297: 280-290

130 Profita M, Chiappara G, Mirabella FR et al. Effect of cilomilast (Ariflo) on TNF-(alpha), IL-8, and GM-CSF release by airway cells of patients with COPD. Thorax 2003; 58: 573-579

131 Timmer W, Leclerc V, Birraux G et al. The new phosphodiesterase 4 inhibitor roflumilast is efficacious in exercise-induced asthma and leads to suppression of LPS-stimulated TNF-alpha ex vivo. J Clin Pharmacol 2002; 42: 297-303

132 Souness JE, Aldous D, Sargent C. Immunosuppressive and anti-inflammatory effects of cyclic AMP phosphodiesterase (PDE) type 4 inhibitors. Immunopharmacology 2000; 47: 127-162

${ }^{133}$ Schmidt BW, Kusma M, Feuring $M$ et al. The phosphodiesterase 4 inhibitor roflumilast is effective in the treatment of allergic rhinitis. J Allergy Clin Immunol 2001; 108: 530-536

134 Bredenboeker D, Syed J, Leichtl S et al. Roflumilast, a new orally active phosphodiesterase 4 inhibitor, is effective in the treatment of chronic obstructive pulmonary disease. Eur Respir J 2002; 20: 374s

135 Crompton CH, Gubb J, Nieman R et al. Cilomilast, a selective phosphodiesterase-4 inhibitor for treatment of patients with chronic obstructive pulmonary disease: a randomised, dose-ranging study. Lancet $2001 ; 358: 265-270$

${ }^{136}$ Grootendorst DC, Gauw SA, Baan R et al. Does a single dose of the phosphodiesterase 4 inhibitor, cilomilast ( $15 \mathrm{mg}$ ), induce bronchodilation in patients with chronic obstructive pulmonary disease? Pulm Pharmacol Ther 2003; 16: 115-120

137 Gamble E, Grootendorst DC, Brightling CE et al. Anti-inflammatory effects of the phosphodiesterase 4 inhibitor cilomilast (Ariflo) in COPD. Am J Respir Crit Care Med 2003; 168: 976-982

138 Kuss H, Hoefgen N, Johanssen S et al. In Vivo Efficacy in Airway Disease Models of N-(3,5-Dichloropyrid-4-yl)-[1-(4-fluorobenzyl)-5-hydroxy-indole-3-yl]-glyoxylic Acid Amide (AWD 12-281), a Selective Phosphodiesterase 4 Inhibitor for Inhaled Administration. J Pharmacol Exp Ther 2003; 307: 373 - 385

${ }^{139}$ Kudoh S. Erythromycin treatment in diffuse panbronchiolitis. Curr Opin Pulm Med 1998; 4: 116-121
140 Tamaoki J. The effect of macrolides on inflammatory cells. Chest 2004; 125: 41S-50S

141 Shoji T, Yoshida S, Sakamoto H et al. Anti-inflammatory effect of roxithromycin in patients with aspitin-intolerant asthma. Clin Exp Allergy 1999; 29: $950-956$

${ }^{142}$ Amayasu H, Yoshida S, Ebana S et al. Clarithromycin suppresses bronchial hyperresponsiveness associated with eosinophilic inflammation in patients with asthma. Ann Allergy Asthma Immunol 2000; 84: 594-598

${ }^{143}$ Kraft M, Cassell GH, Pak J et al. Mycoplasma pneumoniae and Chlamydia pneumoniae in Asthma: Effect of Clarithromycin. Chest 2002; 121: $1782-1788$

${ }^{144}$ Ferrara G, Losi M, Franco F et al. Macrolides in the treatment of asthma and cystic fibrosis. Respir Med 2004; 99: 1 - 10

145 Suzuki T, Yanai M, Yamaya M et al. Erythromycin and Common Cold in COPD. Chest 2001; 120: 730-733

${ }^{146}$ Basyigit I, Yildiz F, Ozkara SKE et al. The Effect of Clarithromycin on Inflammatory Markers in Chronic Obstructive Pulmonary Disease: Preliminary Data. Ann Pharmacother 2004; 38: 1400-1405

147 Banerjee B, Honeybourne D, Khair OA. The effect of oral clarithromycin on bronchial airway inflammation in moderate-to-severe stable COPD: a randomized controlled trial. Treat Respir Med 2004; 3: 59-65

${ }^{148}$ Borok Z, Buhl R, Grimes GJ et al. Effect of glutathione aerosol on oxidant-antioxidant imbalance in idiopathic pulmonary fibrosis. Lancet 1991; 338: 215-216

149 Beeh KM, Beier J, Haas IC et al. Glutathione deficiency of the lower respiratory tract in patients with idiopathic pulmonary fibrosis. Eur Respir J 2002; 19: 1119-1123

150 Behr J, Maier K, Degenkolb B et al. Antioxidative and clinical Effects of high-dose N-Acetylcysteine in fibrosing alveolitis. Am J Respir Crit Care Med 1997; 156: 1897-1901

${ }^{151}$ Cantin AM, Hubbard RC, Crystal RG. Glutathione deficiency in the epithelial lining fluid of the lower respiratory tract in idiopathic pulmonary fibrosis. Am Rev Respir Dis 1989; 139: 370- 372

152 Bowler RP, Crapo JD. Oxidative stress in allergic respiratory diseases. J Allergy Clin Immunol 2002; 110: 349-356

${ }^{153}$ Behr J, Maier K, Braun B et al. Evidence for oxidative stress in bronchiolitis obliterans syndrome after lung and heart-lung transplantation. The Munich Lung Transplant Group. Transplantation 2000; 69: $1856-1860$

${ }^{154}$ Riise GC, Williams A, Kjellstrom C et al. Bronchiolitis obliterans syndrome in lung transplant recipients is associated with increased neutrophil activity and decreased antioxidant status in the lung. Eur Respir J 1998; 12: $82-88$

155 MacNee W. Oxidants/antioxidants and chronic obstructive pulmonary disease: pathogenesis to therapy. Novartis Found Symp 2001; 234: $169-185$

${ }^{156}$ Pela R, Calcagni AM, Subiaco S et al. N-Acetylcysteine reduces the exacerbation rate in patients with moderate to severe COPD. Respiration 1999; 66: $495-500$

157 Stey C, Steurer J, Bachmann S et al. The effect of oral N-acetylcysteine in chronic bronchitis: a quantitative systematic review. Eur Respir J 2000; 16: 253-262

158 Grandjean EM, Berthet P, Ruffmann R et al. Efficacy of oral long-term $\mathrm{N}$-acetylcysteine in chronic bronchopulmonary disease: a meta-analysis of published double-blind, placebo-controlled clinical trials. Clin Ther 2000; 22: 209-221

159 Benedetto F de, Aceto A, Dragani B et al. Long-term oral n-acetylcysteine reduces exhaled hydrogen peroxide in stable COPD. Pulm Pharmacol Ther 2005; 18: $41-47$

${ }^{160}$ Kasielski M, Nowak D. Long-term administration of N-acetylcysteine decreases hydrogen peroxide exhalation in subjects with chronic obstructive pulmonary disease. Respir Med 2001; 95: 448-456

${ }^{161}$ Decramer M, Rutten-van Mölken M, Dekhuijzen PN et al. Effects of $\mathrm{N}$-acetylcysteine on outcomes in chronic obstructive pulmonary disease (Bronchitis randomized on NAC Cost-Utility Study, BRONCUS): a randomised placebo-controlled trial. Lancet 2005; 365 : $1552-1560$

162 Malerba M, Ponticello A, Radaeli A et al. Effect of twelve-months therapy with oral ambroxol in preventing exacerbations in patients with COPD. Double-blind, randomized, multicenter, placebo-controlled study (the AMETHIST Trial). Pulm Pharmacol Ther 2004; 17: 27-34 
163 Antonicelli F, Brown D, Parmentier M et al. Regulation of LPS-mediated inflammation in vivo and in vitro by the thiol antioxidant Nacystelyn. Am J Physiol Lung Cell Mol Physiol 2004; 286: L1319-L1327

${ }^{164}$ Nagy AM, Vanderbist F, Parij $\mathrm{N}$ et al. Effect of the mucoactive drug nacystelyn on the respiratory burst of human blood polymorphonuclear neutrophils. Pulm Pharmacol Ther 1997; 10: 287-292

${ }^{165}$ App EM, Baran D, Dab I et al. Dose-finding and 24-h monitoring for efficacy and safety of aerosolized Nacystelyn in cystic fibrosis. Eur Respir J 2002; 19: 294-302

${ }^{166}$ Leckie MJ, ten Brinke A, Khan J et al. Effects of an interleukin-5 blocking monoclonal antibody on eosinophils, airway hyper-responsiveness, and the late asthmatic response. Lancet 2000; 356: 2144-2148

167 Gabrijelcic J, Acuna A, Profita M et al. Neutrophil airway influx by platelet-activating factor in asthma: role of adhesion molecules and LTB4 expression. Eur Respir J 2003; 22: 290-297

168 Nightingale JA, Rogers DF, Hart LA et al. Effect of inhaled endotoxin on induced sputum in normal, atopic, and atopic asthma subjects. Tho$\operatorname{rax} 1998 ; 53: 563-571$

169 Brightling CE, Monterio W, Green RH et al. Induced sputum and other outcome measures in chronic obstructive pulmonary disease: safety and repeatability. Respir Med 2001; 95: 1999-2002

170 Senn S. Sample size issues. In: Senn S (ed.). Crossover trials in clinical research, 2. ed. Chichester: Wiley \& Sons Ltd, 2002: 277-286

171 Belda J, Leigh R, Parameswaran K et al. Induced sputum cell counts in healthy adults. Am J Respir Crit Care Med 2000; 161: 475-478

172 Pizzichini MMM, Popov TA, Efthimiadis A et al. Spontaneous and induced sputum to measure indices of airway inflammation in asthma. Am J Respir Crit Care Med 1996; 154: 866 - 869

173 Beier J, Beeh KM, Semmler D et al. Increased concentrations of glutathione in induced sputum in patients with mild or moderate allergic asthma. Ann Allergy Asthma Immunol 2004; 92: 459-463

174 Stanescu D, Sanna A, Veriter C et al. Airways obstruction, chronic expectoration, and rapid decline of FEV1 in smokers are associated with increased levels of sputum neutrophils. Thorax 1996; 51: 267-271

175 Culpitt SV, Matos C de, Russell RE et al. Effects of theophylline on induced sputum inflammatory indices and neutrophil chemotaxis in chronic obstructive pulmonary disease. Am J Respir Crit Care Med 2002; 165: $1371-1376$

${ }^{176}$ Loppow D, Schleiss MB et al. In patients with chronic bronchitis a four week trial with inhaled steroids does not attenuate airway inflammation. Respir Med 2001; 95: 115-121

177 Silkoff PE, Martin D, Pak J et al. Exhaled nitric oxide correlated with induced sputum findings in COPD. Chest 2001; 119: 1049-1055

178 Paredi P, Kharitonov SA, Loukides S et al. Exhaled nitric oxide is increased in active fibrosing alveolitis. Chest 1999; 115: 1352-1356

179 Gessner C, Hammerschmidt S, Kuhn H et al. Gehauchte Diagnosen? Zum Potenzial von Atemkondensatuntersuchungen. Pneumologie 2004; 58: 230-237

${ }^{180}$ Kharitonov SA. Exhaled markers of inflammatory lung diseases: ready for routine monitoring? Schweiz Med Wschr 2003; 134: 175 - 192

181 Godaly G, Hang L, Frendeus B et al. Transepithelial Neutrophil Migration Is CXCR1 Dependent In Vitro and Is Defective in IL-8 Receptor Knockout Mice. J Immunol 2000; 165: 5287-5294

182 Beeh KM, Beier J, Ernst M et al. Platinum-based, leukocyte-depleting chemotherapy does not alter induced sputum markers of neutrophilic inflammation in COPD-patients with unresectable non-small-cell lung cancer. Respiration 2003; 70: 166-171

\section{Erratum}

Akute myeloische Leukämie mit pulmonaler

Manifestation

\section{E. Schalk, A. Franke, M. Koenigsmann}

Pneumologie 2005; 59: 588-591

Hier wurde eine falsche Korrespondenzadresse abgedruckt. Nachstehend die korrekte Adresse.

Enrico Schalk · Universitätsklinikum Magdeburg · Klinik für Hämatologie/Onkologie · Leipziger Straße 44 . 39120 Magdeburg·E-mail: fuhse@web.de 